\title{
EXPLORING THE EXPERIENCE OF RECEIVING CANADIAN ARMED FORCES' MENTAL HEALTH SERVICES
}

by

Erin O’Rourke, BSW, Ryerson University, 2012

\author{
A major research paper \\ presented to Ryerson University \\ in partial fulfillment of the \\ requirements for the degree of \\ Master of Social Work \\ in the program of Social Work
}

Toronto, Ontario, Canada, 2014

CErin O’Rourke 2014 


\author{
AUTHOR'S DECLARATION FOR ELECTRONIC SUBMISSION OF A MRP \\ I hereby declare that I am the sole author of this MRP. This is a true copy of the MRP, including \\ any required final revisions. \\ I authorize Ryerson University to lend this MRP to other institutions or individuals for the \\ purpose of scholarly research \\ I further authorize Ryerson University to reproduce this MRP by photocopying or by other \\ means, in total or in part, at the request of other institutions or individuals for the purpose of \\ scholarly research. \\ I understand that my MRP may be made electronically available to the public.
}




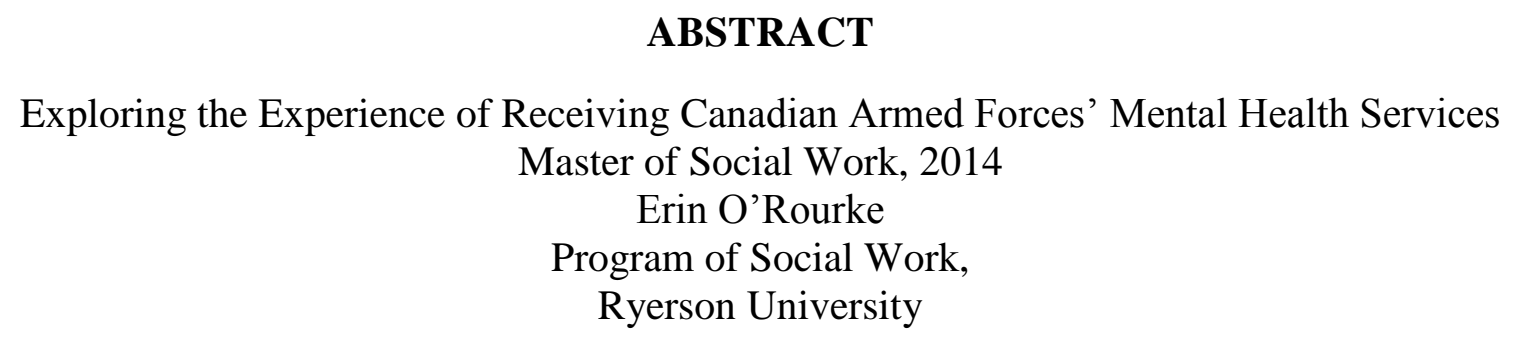

This study uses a narrative approach to explore the experience of receiving mental health services within the Canadian Armed Forces (CAF). Data was collected from media sources where interviews were conducted with current and former CAF members about their experiences with the CAF's mental health services. Thematic narrative analysis was used to interpret themes that emerged within participants' stories and to identify similarities and differences across stories. Findings included the experience of structural difficulties when accessing the CAF's mental health services, the negative effects of mental health stigma, fears related to disclosing issues of mental health and the need for changes to the CAF's mental health system. The study also presents a preliminary discussion on the relevance of anti-oppressive social work practice for the CAF's mental health services. Also detailed is the process of completing the research including the challenges encountered when attempting to access the population and recruit participants. 


\section{ACKNOWLEDGEMENTS}

I would like to thank Susan Preston, my MRP supervisor, whose guidance and support has been instrumental toward completing this research project. Thank you also to my family, friends and peers for your continuous support and encouragement throughout this year. 


\section{TABLE OF CONTENTS}

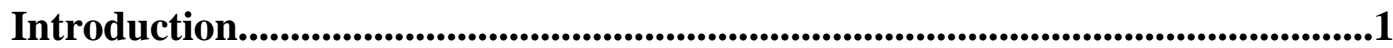

Chapter 1: Literature Review..........................................................................................4

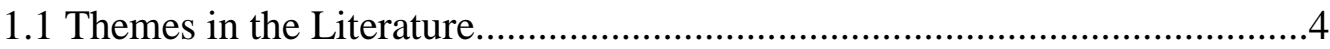

1.2 Findings in Military Mental Health Literature..................................................5

1.3 Findings in Mental Health and AOP Literature...........................................

1.4 Theoretical and Methodological Review of Literature.................................

1.5 Gaps in the Literature..................................................................................

1.6 MRP Aims and Research Question...........................................................13

1.7 Importance of the Research.........................................................................13

Chapter 2: Theoretical Framework...............................................................................16

Chapter 3: Methodology.........................................................................................................22

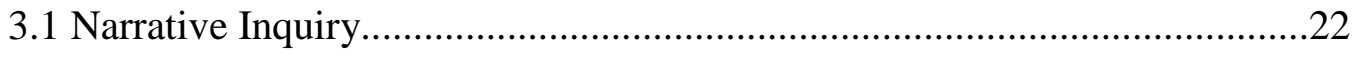

3.2 Why Narrative Research?.......................................................................24

3.3 Intended Research Approach....................................................................

3.4 Attempting the Intended Research Approach: Findings..................................30

3.5 Actual Research Approach.............................................................................33

Chapter 4: Findings...................................................................................................................41

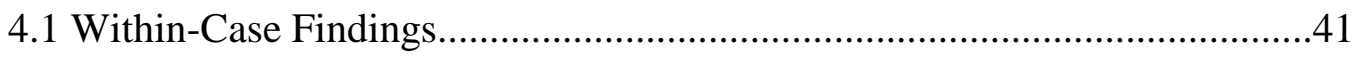

Tim Boyce ..............................................................................................

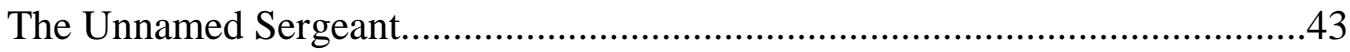

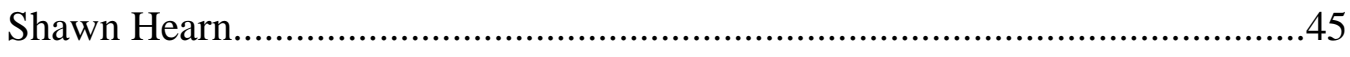

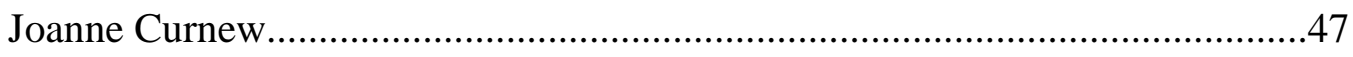

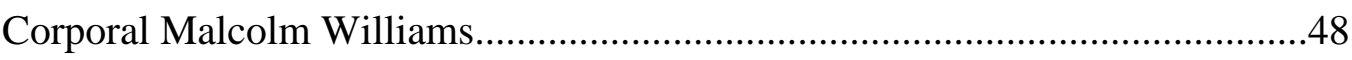

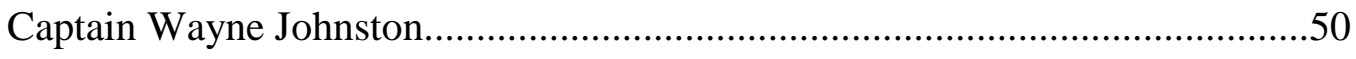

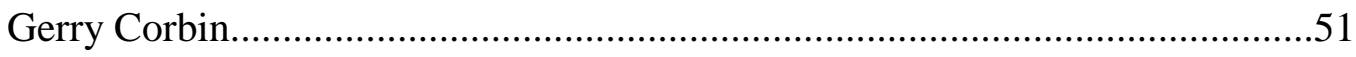

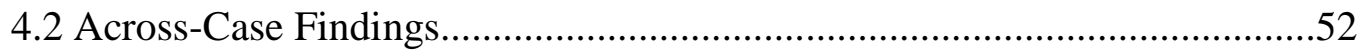


Chapter 5: Discussion.........................................................................................................55

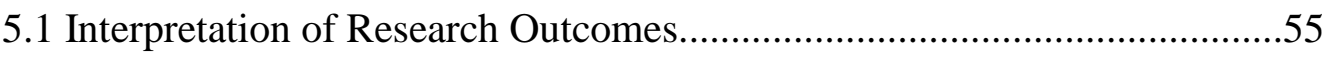

5.2 Comparison of Research Outcomes to Other Study Findings......................59

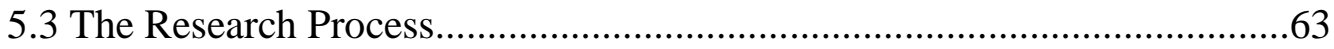

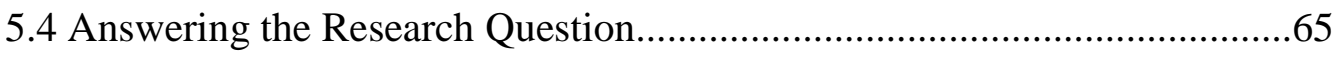

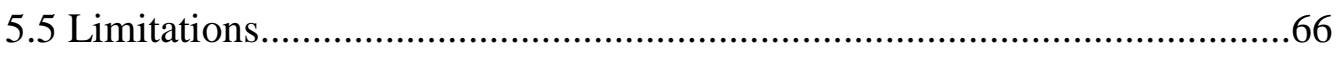

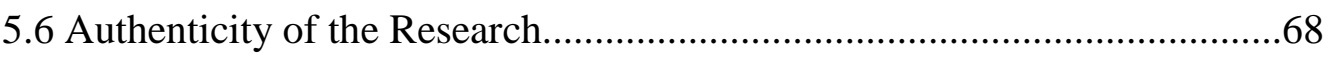

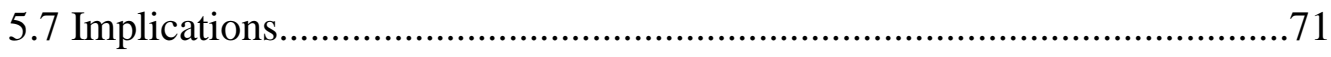

Conclusion.......................................................................................................................................74

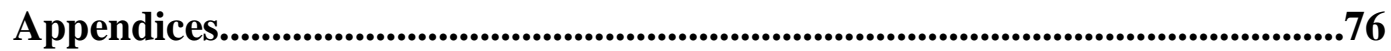

References....................................................................................................................................82 


\section{LIST OF APPENDICES}

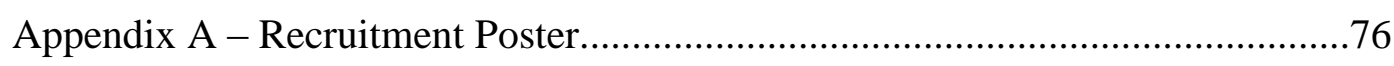

Appendix B - Interview Guide............................................................ 77

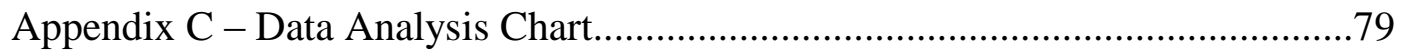




\section{INTRODUCTION}

There is growing awareness concerning the mental health of Canadian Armed Forces (CAF) personnel. With the CAF's involvement in recent large-scale operations such as the mission in Afghanistan there has been resurgence in recognition of the adverse effects that combat and other high risk activities common in conflict zones can have on the mental health of military personnel. In addition, the suicides of four CAF members in late 2013 have also increasingly brought the issue to the attention of the Canadian public. In response to these events, an unprecedented video to the troops was released late last year by the Chief of the Defence Staff General Tom Lawson speaking directly about military mental health (National Defence and the Canadian Armed Forces, 2013a).

Despite the prevalence and urgency of the issue, there is limited research that focuses on how the CAF is responding to the mental health needs of its personnel or on ways of enhancing services. Also missing is research that looks at the role of social work in this area of service delivery. Even more specifically, the use of anti-oppressive (AOP) social work practice within a military context is currently absent from the literature.

This major research paper (MRP) fills a gap by uncovering what the stories of current and former CAF personnel can inform us about the experience receiving mental health services within the CAF. It also offers a preliminary discussion based on those stories, of whether and how AOP social work can contribute to or enhance the CAF's current mental health services.

As someone who grew up in a family with a long history of military service in the CAF, the issues experienced by this population are of personal relevance. Further, as a social worker interested in practicing with the military community, I am interested in hearing the stories of current and former CAF personnel to learn about their experiences receiving mental health services within the CAF. More specifically, as a social worker educated and trained in AOP, I 
am also interested in exploring whether and how this practice approach can contribute to or enhance current mental health services delivered by the CAF.

\section{MRP Outline}

The MRP begins with a literature review of the substantive topic areas related to this research. Included is a review of the themes and findings of studies related to the mental health of military personnel and the use of AOP in mental health services. A theoretical and methodological review of this literature is also presented. Gaps in the literature are identified with discussion of how these gaps informed the development of the research question and design

of this study. Also detailed is discussion about why this research is important, how it contributes to AOP social work practice and what can be learned from the study.

The MRP then details the theoretical framework guiding the research. Specifically, a description of AOP including the theories that inform this perspective is presented. Also discussed are some of the theoretical tensions surrounding the use of an AOP framework. The specific tenets of AOP selected to guide the research are identified and described for their relevancy.

Following this, the research methodology of the study is detailed. A narrative approach to research is described and justification is provided for why this approach was selected. Staying true to the narrative approach, the story of the research process that unfolded while completing this research project is also presented. This involves detailing both the intended and actual methods of conducting the research. The specific narrative approach suggested by Riessman $(2005 ; 2007)$ used in the research design of this study is described including the methods of data collection and data analysis. 
The MRP then presents the findings of data analysis. A brief summary of each participant's story is provided and the themes that emerged within each story are detailed. The similarities and differences found across participants' stories are also presented.

The final chapter of the MRP provides a discussion of interpretations of the research outcomes and process, specifically as they relate to the theoretical framework, methodology and literature guiding the research. The limitations and authenticity of the study are also detailed. Finally, implications of the research for social work practice are provided and include a preliminary discussion of the ways in which AOP social work can contribute to the CAF's current mental health services. 


\section{CHAPTER 1. LITERATURE REVIEW}

A review of the literature related to the topic of my research, involved looking at studies focused on two areas of substantive content. The first topic area relevant to my research, involved searching for studies related to the mental health of military personnel. This composed the largest part of the literature review. A smaller scan of the literature on the second topic area relevant to my research involved searching for studies that looked at the use of AOP within mental health services or settings. This topic was a smaller focus as it is used only to inform the secondary aim of this study which is to offer a preliminary discussion exploring whether and how AOP social work can contribute to or enhance the CAF's current mental health services.

The chapter begins with a brief overview of the themes and findings that emerged within the literature. Following this, a theoretical and methodological review of the literature is provided and the gaps that exist within the literature are detailed. The aims and research question guiding the study are presented and are followed by a discussion on the importance of this research study.

\subsection{Themes in the Literature}

Regarding the studies related to the mental health of military personnel, various themes emerged in the literature. These include the rates and prevalence of military personnel experiencing issues of mental health (Boulos \& Zamorski, 2013; Fear et al., 2010; Fikretoglu, Brunet, Guay \& Pedlar, 2007; Milliken, Auchterlonie \& Hoge, 2007; Sareen et al., 2007; Sareen et al., 2008; Seal et al., 2009); the factors associated with receiving a mental health diagnosis and the most common diagnoses experienced (Fikretoglu et al., 2007; Sareen et al., 2007; Sareen et al., 2008); utilization of mental health services by military personnel (Elbogen et al., 2013; Fikretoglu, Brunet, Guay \& Pedlar, 2008; Fikretoglu, Liu, Pedlar \& Brunet, 2010; Hoge, Auchterlonie \& Milliken, 2006); and the barriers to receiving care (Castro, Cotting, Hoge, 
Koffman, McGurk \& Messer, 2004; Drapalski, Milford, Goldberg, Brown \& Dixon, 2008; Kim, Britt, Klocko, Riviere \& Adler, 2011; Pietrzak, Johnson, Goldstein, Malley \& Southwick, 2009; Stecker, Fortney \& Sherbourne, 2011; Sudom, Zamorski \& Garber, 2012).

In searching the literature, I found only a modest number of studies that focused specifically on the mental health of CAF personnel and on the CAF's mental health services (Boulos \& Zamorski, 2013; Fikretoglu et al., 2007; Fikretoglu et al., 2008; Fikretoglu et al., 2010; Sareen et al., 2007; Sareen et al., 2008; Sudom et al., 2012). For this reason, studies related to the mental health of military personnel and veterans from both the United States and the United Kingdom were also reviewed (Castro et al., 2004; Drapalski et al., 2008; Elbogen et al., 2013; Fear et al., 2010; Hoge et al., 2006; Kim et al., 2011; Milliken et al., 2007; Pietrzak et al., 2009; Seal et al., 2009; Stecker et al., 2011).

In searching the literature related to the use of AOP in mental health services, I found a limited number of studies on this topic. Themes emerging from these studies included the application of anti-oppressive principles and practices within mental health services (Larson, 2008; Poole et al., 2012; Smith, 2011) and some of the challenges associated with implementing AOP principles within mental health settings (Larson, 2008; Smith, 2011).

\subsection{Findings in Military Mental Health Literature}

A first theme in the findings of studies related to the mental health of military personnel regards the rates and prevalence of mental health diagnoses experienced by this population. Within the CAF, up to $15 \%$ of all personnel experience symptoms related to a mental disorder (National Defence and the Canadian Armed Forces, 2013b). Also significant is the small number of personnel within the CAF who do not have a formal diagnosis of a mental illness, but whose levels of distress may be having an impact on their daily lives (National Defence and the 
Canadian Armed Forces, 2013b). Similar rates of mental health diagnoses have been found within militaries from both the United States and the United Kingdom (Fear et al., 2010; Milliken et al., 2007). Understanding the rates of mental health distress and diagnoses among military personnel helps to provide context on the prevalence of the issue and why it is necessary that efforts aimed at addressing the problem, such as continued research, be made.

Another common finding across the literature is the relation between receiving a mental health diagnosis and exposure to combat or other high risk military operations (Boulos \& Zamorski, 2013; Castro et al., 2004; Fear et al., 2010; Milliken et al., 2007; Sareen et al., 2007; Sareen et al., 2008; Seal et al., 2009). A minority, 13.5\% of CAF personnel deployed in support of the Afghanistan mission, received a mental health diagnosis perceived to be related to the deployment (Boulos \& Zamorski, 2013). The relation between combat exposure and mental health diagnoses is relevant because of the CAF's recent involvement with the mission in Afghanistan which was the largest and most dangerous combat operation undertaken by the Canadian military since the Korean War (National Defence and the Canadian Armed Forces, 2013b).

The most common mental health diagnoses experienced by veterans and active military personnel include major depression, social phobia, posttraumatic stress disorder (PTSD), panic disorder, generalized anxiety disorder, and substance use disorders (Boulos \& Zamorski, 2013; Castro et al., 2004; Fear et al., 2010; Milliken et al., 2007; Sareen et al., 2008; Seal et al., 2009; National Defence and the Canadian Armed Forces, 2013b). This helps to provide context as to the types of mental health issues commonly encountered by military personnel which can assist with understanding the symptoms and circumstances they may experience. 
Despite the prevalence of mental health issues among military personnel, another common finding across the literature is that many of these individuals do not access mental health services (Castro et al., 2004; Fikretoglu et al., 2007; Fikretoglu et al., 2008; Fikretoglu et al., 2010; Hoge et al., 2006; Sareen et al., 2007; Sudom et al., 2012; National Defence and the Canadian Armed Forces, 2013b). Failure to initiate treatment in a timely manner was found to be a major mental health service access issue in the CAF (Fikretoglu et al., 2010) with less than half of CAF personnel with a mental health diagnosis seeking care in any given year (National Defence and the Canadian Armed Forces, 2013b). It is important to understand whether military personnel are accessing mental health services as it helps to inform whether available resources are being sought or utilized. As these findings indicate, not all military personnel needing mental health services are accessing them prompting a need to uncover the reasons why this occurs.

When exploring the barriers to receiving mental health care among military populations, a common finding is that lack of utilization is related to negative attitudes toward mental health treatment, beliefs that services would be ineffective or harmful, desires to manage mental health issues on one's own, concerns about career impact of seeking care and negative stigma (Castro et al., 2004; Fikretoglu et al., 2008; Kim et al., 2011; National Defence and the Canadian Armed Forces, 2013b; Sudom et al., 2012;). In addition to these barriers, CAF members have also been found to have a lack of trust in military health, administrative, and social services (Fikretoglu et al., 2008).This lack of trust could deter CAF members from accessing care or negatively impact on the experience of receiving it. Knowing about these barriers to receiving mental health services is important as they help to explain why military personnel may choose not to seek out or receive needed care. 


\subsection{Findings in Mental Health and AOP Literature}

When looking at the literature related to the application of anti-oppressive principles and practices within mental health services, findings state that this can be achieved by promoting education about mental health to service users and providers, deconstructing and challenging the medical model, using respectful language, shifting the negative discourse surrounding issues of mental health, including service users in all aspects of care and offering alternative healing perspectives and approaches (Larson, 2008; Poole et al., 2012; Smith, 2011). Understanding the ways in which principles and practices of AOP can be incorporated into mental health services helps to inform the exploration of whether and how such methods could be relevant to the CAF's mental health services.

The findings of the literature that explore some of the challenges associated with implementing AOP principles within mental health settings include practicing within a neoliberal context, having large and demanding caseloads, having limited time to devote to AOP efforts such as advocacy, having little time or energy to challenge the existing organizational structure of mental health settings and fear of job loss for challenging or resisting current methods of practice (Larson, 2008; Smith, 2011). Knowing some of the challenges associated with implementing AOP within mental health settings provides insight into issues that could also be encountered within the CAF's mental health services. This further informs the discussion exploring the relevancy of AOP within this practice context.

The substantive findings of the literature related to military mental health show the prevalence of mental health diagnoses and distress among the population, the relation between combat exposure and mental health diagnosis, the most common types of diagnoses experienced, a lack of utilization of military mental health services and the barriers to receiving care. Taken 
together, these findings help to inform us about the current state of military mental health and mental health services. Similarly, the substantive findings of the literature related to the use of AOP within mental health services including the ways in which AOP principles and practices can be applied within such settings and the challenges involved help to inform a discussion exploring the relevancy of AOP for the CAF's mental health services.

\subsection{Theoretical and Methodological Review of the Literature}

Undertaking a theoretical and methodological review of the literature is an important process as those who are involved in knowledge construction directly affect what is known about the topic and how it is known (Creswell, 2013). In completing a theoretical review of the literature, the studies represented a limited assortment of theoretical perspectives. The most common theoretical underpinning observed was a modernist perspective. Modernism holds that truth and knowledge can be discovered, examined, understood and explained through rational and scientific means and then controlled, used and exploited for the betterment of the human condition (Mullaly, 2002).

This modernist perspective can be seen in the largely positivist approach to the studies reviewed which often attempted to understand the issue of military personnel's mental health by collecting information in the form of quantitative data and using rational and scientific means, often medical perspectives or approaches, to understand and explain the issue (Castro et al., 2004; Elbogen et al., 2013; Fikretoglu et al., 2007; Sudom, Zamorski \& Garber, 2012). This was with the aim of finding ways to effectively address or treat the mental health issues being experienced. Further, the knowledge generated by these studies is assumed to be free of bias, unattached to power or ideology and assumed to be neutrally discovered by expert researchers, other key features that demonstrate the positivist nature of the literature reviewed. 
The use of solely quantitative approaches to research on the topic of military mental health is problematic because it limits the full extent of knowledge that can be generated. For example, using quantitative methods can work to exclude the knowledge of those whom the research concerns (Potts \& Brown, 2005). Due to the quantitative nature of the research methods employed in the studies reviewed, the beliefs, thoughts and perspectives of participants were not directly used in the formulation of knowledge. This is because quantitative research involves developing techniques and employing methods that prioritize quantitative data (i.e., data in the form of numbers) (Neuman \& Robson, 2009). As such, the focus is on an aggregate representation of experiences and less on the unique experiences reflected in individual participant voices. This is problematic because numerical data is only a single form of information, and generalizes experiences. In contrast, data in qualitative research comes in various shapes, sizes and forms including the written or spoken words of participants, and often focuses on the uniqueness of individual experiences. Explanations based on qualitative data tend to be rich in detail, sensitive to context and capable of showing the complex processes or sequences of social life (Neuman \& Robson, 2009).

More specific to data collection, the use of standardized surveys and questionnaires, in the quantitative studies I examined, limited the responses that participants could select as they could only choose from pre-determined responses they felt best approximated their experience or opinion. This is as opposed to having the unrestricted ability to do so which can be achieved through the use of more qualitative methods such as interviews. In this way, the voices and narratives of those whom the research concerns are not included in these studies and as such they are excluded from creating knowledge about issues of which they are the expert (Potts \& Brown, 2005). 
A modernist perspective can also be seen in these studies by the use of more medicalized understandings and approaches to mental health. Researchers belonged mainly to the fields of medicine and psychology, disciplines which are influenced by dominant perspectives on mental health, specifically the medical model. In the studies reviewed, this can be seen for example through the use of medical language and labels (e.g., mental health, mental illness, and diagnosis), reliance on medically-oriented diagnostic and assessment tools (e.g., Diagnostic and Statistical Manual of Mental Disorders), and biologically based interventions (e.g., medications). This is problematic as the medical model presents only one perspective used toward understanding issues of mental health and can reproduce a discourse which is argued to contribute toward sanism (Larson, 2008; Poole et al., 2012).Sanism can then result in the negative treatment of individuals affected by issues of mental health.

A methodological review of the literature related to the mental health of military personnel revealed that only quantitative methodologies were employed in the studies which are evidenced by their highly empirical nature (Boulos \& Zamorski, 2013; Fear et al., 2010; Sareen et al., 2007; Sareen et al., 2008). Commonly, quantitative methods of data collection were used often in the form of questionnaires or surveys. Studies also relied on quantitative methods of data analysis including outcome measures and statistical analyses. This is problematic, as is similarly noted above, because relying solely on such methods can limit and affect the type of knowledge produced. Employing qualitative methods, such as interviews, can elicit more rich and detailed information (Creswell, 2013) that can further contribute to or enhance knowledge on the subject.

\subsection{Gaps in the Literature}

A review of the literature related to the two areas of substantive content relevant to my research, reveals certain gaps. The majority of studies related to the mental health of military 
personnel and the mental health services they received utilized quantitative methodologies, were conducted outside of Canada and were completed by researchers outside the discipline of social work. The use of AOP within a military context, and even more specifically within military mental health services, is currently absent from the literature. These gaps are significant because they offer limited perspectives and approaches toward understanding the issue, specifically as it relates to the Canadian context. Missing from the literature is research on the issue conducted from an AOP social work perspective which can offer further insights not yet explored.

These gaps have resulted in the voices and experiences of CAF personnel who have received mental health services within the CAF going unheard. Consequently, there is a limited understanding of what the experience receiving the CAF's mental health services is like from the perspective of those who understand it best and who as such can offer the most knowledge and expertise on the topic. Further missing is the perspective of AOP social work when it comes to delivering mental health services within a military context, which as a result neglects to consider the potential for this practice approach to contribute toward addressing the mental health issues experienced by military personnel. AOP is particularly relevant for this practice area because of its focus on challenging forms of oppression including those related to mental health such as sanism (Poole et al., 2012). Further, as AOP centres issues of power (Mullaly, 2002) it offers an approach that contrasts the highly regimented power structure of military organizations. Because of these gaps, a literature review specific to my topic was a difficult undertaking as I could not locate a single study that mirrored my goals. However, identifying these gaps was crucial for they directly influenced the development of the research question and aims that drive this study. 


\subsection{MRP Aims and Research Question}

Based on what is known and what is missing in the literature about the topics related to my research, I have been left to wonder the following question: what can the stories of current or former CAF personnel inform us about the experience of receiving mental health services within the CAF? Of secondary interest is how these stories can be used to guide a preliminary discussion about whether and how AOP social work can contribute to or enhance current mental health services within the CAF.

This study answers this research question by looking at the stories of current or former CAF personnel and analysing them to learn about their experiences. These stories are also used to guide a preliminary discussion exploring the relevance of AOP social work within the CAF's mental health services. In doing so, this research generates new knowledge about what the experience is like for CAF personnel to receive mental health services within the CAF and offers a preliminary exploration of how AOP social work can contribute to what is currently being done.

\subsection{Importance of the Research}

Topics related to the experience of receiving mental health services within the CAF and on potential ways in which these services may be enhanced are important areas for research. Nearly 40,000 CAF personnel have served in Afghanistan with up to $13.5 \%$ of these personnel receiving a mental health diagnosis perceived to be related to the deployment (Boulos \& Zamorski, 2013). Add to this the fact that many of the 120,000 CAF personnel who have served as United Nations peacekeepers experience trauma rates as high as Afghan veterans (National Defence and the Canadian Armed Forces, 2013b), and the urgency of the issue becomes heightened. Even more alarming is that the incidence of mental health issues can double with 
passing years, meaning that close to $30 \%$ of those involved in combat operations may need significant psychological and other support over many years (National Defence and the Canadian Armed Forces, 2013b). This speaks to the need for research that explores how the CAF's mental health services can meet the needs of its personnel.

The prevalence of CAF personnel experiencing mental health issues also has important implications for service delivery. Since the early 2000s, the CAF has invested heavily in its mental health system and as a result, now has about twice as many mental health clinicians per capita as the Canadian general population (Sudom, Zamorski \& Garber, 2012). This is relevant to social workers who compose an integral part of the interdisciplinary team that comprises the CAF's Health Services. This includes both social work officers who are members of the CAF as well as civilian social workers whose services are outsourced by the military. Despite this, minimal research has looked at the role of social work in addressing the mental health needs of CAF personnel. Even more specifically, the use of AOP social work practice within a military context is currently absent from the literature. As such, the potential contributions of this practice approach toward addressing the mental health needs of military personnel have yet to be explored. With its focus on forms of oppression such as sanism and its ability to contrast the regimented power structure of military organizations, AOP can be particularly relevant for this area of practice.

In these ways, this research is important because it helps to fill these gaps by providing an opportunity to learn what the stories of CAF personnel can inform us about their experiences receiving mental health services within the CAF. This can offer valuable information that has yet to be uncovered. This information can also be beneficial toward guiding a discussion exploring whether and how AOP social work can contribute to or enhance the CAF's current mental health 
services. This contributes to AOP social work by offering insight about how this practice framework can be implemented within military organizations, a context of service delivery that has yet to be explored in the literature. 


\section{CHAPTER 2.THEORETICAL FRAMEWORK}

As this study has AOP as a secondary substantive focus resulting from my interest in exploring the relevance of this type of practice for the CAF's mental health services, the underlying theoretical framework guiding the research consists of certain tenets drawn from an AOP approach. AOP is a social justice-oriented approach to social work theory and practice that attempts to integrate efforts aimed at social change directly into the social work experience (Baines, 2007). These efforts can take the form of new practices, new ways of understanding and building knowledge, and new methods of activism and resistance (Baines, 2007). In a general sense, anti-oppressive social workers provide direct services but also strive to help clients and themselves understand that problems are linked to social inequality which can be challenged or changed through the use of various methods and strategies (Baines, 2007; Dominelli, 2002; Mullaly, 2002).

Rather than being a single, unified theory or approach, AOP is an umbrella term that borrows and draws on a number of social justice-oriented approaches (Baines, 2007). These approaches are informed by various theories including critical, structural, Marxist, post-modern, post-structural, feminist, anti-racist, queer and Indigenous theories. This collection of theoretical understandings all share social justice as their foundation, however each approach draws on a different lens. In this way, AOP allows us to view and interrogate social issues from multiple perspectives. This can be quite effective for practice and research as it allows for flexibility that can open up and guide various possibilities of understanding and acting upon social problems.

Utilizing a theoretical framework with a focus on social justice is beneficial for the purpose of this research as it seeks to contribute toward understanding and finding ways to address the social issues experienced by military personnel, specifically those related to issues of mental health. The flexibility of an AOP approach allows for understandings of this social issue 
to be generated by drawing on multiple perspectives as opposed to the largely modernist and medicalized theories more commonly used in research concerning mental health. It is for these reasons that I have selected to use an AOP approach for the purpose of this research.

The use of an AOP approach at a theoretical level however, has raised certain tensions. Some scholars, particularly post-modern and post-structural theorists, have argued that AOP dilutes components of their critiques by moving quickly to concrete, collective programs and practices (Baines, 2007). Those promoting class or race analyses for example, fear that their central concerns may not receive sufficient attention within a multiple oppressor framework (Razack \& Jeffrey, 2002; Williams, 1999). Another limitation of AOP in social work is its lack of focus at a micro and individual level (Sakamoto \& Pitner, 2005). Further, it has also been argued that AOP theorists do not adequately address the impact of institutional context on the development and application of anti-oppressive principles (Healy, 2005) and as such proponents of AOP fail to consider how it may be easier to choose and work from this model in some contexts more than others.

Despite these tensions, an AOP lens is beneficial for the purpose of this study. The multiple theories that inform this approach allow me the flexibility to draw on certain perspectives particularly relevant to my research. Due to its broad scope however, I have selected certain core tenets of AOP that I feel are particularly helpful in guiding my understanding and approach to this study. These tenets include an understanding of the ways in which oppressive forces create and affect the social problems people experience (Mullaly, 2002); a focus on the impact of power dynamics in service delivery (Dominelli, 2002); and the view that people are experts of their own lives (Dominelli, 2002). AOP as a theoretical framework allows me to hold 
these tenets together in a singular approach as opposed to piecing together multiple theories to create a framework conducive to my research, thus strengthening its theoretical rigor.

The first tenet of an AOP approach relevant to my research involves understanding how oppressive forces create and affect the social problems people experience. Any anti-oppressive social work, including social work research, must make the source and situation of oppression a central focus (Mullaly, 2002). By centering oppression, an AOP approach links the personal to the political wherein it is understood that seemingly private problems belonging to individuals are in fact public problems belonging to a society characterized by oppression (Mullaly, 2002). This can assist researchers, practitioners and clients to identify the social causes of situations thereby reducing the tendency to blame the individual or group for the problems they experience.

I have selected to use this tenet of AOP for its potential to place emphasis on a specific form of oppression that could be present in the experiences of participants involved in my research. Specifically, this form of oppression is sanism, described as the systematic subjugation of people who have received mental health diagnoses or treatment (Poole et al., 2012).Use of the medical model is pervasive in the literature on military mental health, and sanism is often reflected in that approach (Larson, 2008). Using an AOP approach can assist in recognizing and critically interrogating how sanism as a form of oppression may influence the experiences of current or former CAF personnel who have received mental health services. This perspective can also be beneficial when discussing the potential for AOP social work to contribute to or enhance current mental health services within the CAF as it brings forward an approach to service delivery that previous studies related to this topic have yet to consider. More specifically, an AOP approach may offer insight as to how forms of oppression such as sanism can impact on the experience of receiving mental health services. 
Another tenet of AOP guiding my research is the belief that people are experts of their own lives. Acknowledging client's agency and validating their own knowledge base as a source of expertise is crucial to AOP (Dominelli, 2002). This is important from an AOP perspective because it places those with lived experience of an issue in the position of the expert thereby showing value and respect for their knowledge. I have selected to use this tenet for its potential to generate new knowledge about what the experience of receiving mental health services within the CAF is like from the perspective of those who have actually lived through such an experience. This is important to my research which relies on the knowledge offered by current and former CAF members in the form of their stories of experience.

As previously mentioned, much of the existing literature related to this topic comes from research studies that used quantitative methods of data collection. This lack of variability in research methods may result in producing a limited or incomplete knowledge base as the more detailed and in-depth information uncovered through qualitative research approaches may not be captured. Using a methodology, specifically narrative inquiry, that centres the stories of participants' lived experiences as the unit of analysis, creates an opportunity to access information previously uncovered. In this way, the methodology selected for my research is guided by a central tenet of AOP which emphasizes that the experiences of those affected by an issue are a key starting point in the development of new theory, knowledge, and practice (Baines, 2007).

The final tenet of AOP guiding my research involves focusing on the impact of power dynamics in service delivery. Conceptualizing encounters, whether in research or practice, as involving both parties as subjects who exercise agency is particularly relevant in AOP (Dominelli, 2002). Here, the professional, recognizes their greater contextual power and engages 
in efforts aimed at power-sharing and empowerment of the client or participant by reducing power differentials between them (Dominelli, 2002). Analysing encounters in this way has the impact of challenging expert knowledge and generating ways of working and promoting egalitarian partnerships that draw upon power-sharing to foster equality (Dominelli, 2002).

This tenet has the potential to contrast the regimented and authoritarian organizational culture of military organizations which are based on strict power hierarchies. This type of organizational culture may have the potential to permeate and function within all branches of the CAF, including its Health Services which is responsible for the delivery of mental health services. Power plays out in the CAF through the chain of command in which those personnel of higher rank have increased levels of authority and as such hold greater power. AOP offers a perspective that can identify and critically analyze how these power dynamics may affect the experience of receiving mental health services within the CAF.

Further, this tenet also offers a relevant perspective that can assist with the discussion as to whether and how AOP social work can contribute to or enhance current mental health services within the CAF. AOP theorists acknowledge that the processes of service delivery can serve to oppress or empower and as such, AOP promotes changes at an institutional level to the organization and delivery of services (Healy, 2005). An AOP perspective can give insight into the ways in which issues of power can be addressed in the CAF's mental health services. This can include finding ways to promote a more equal exchange of power between practitioners and service users. This can be beneficial as a relationship that is based on a more equal partnership can encourage meaningful dialogue (Mullaly, 2002) and promote service user involvement in decision making (Healy, 2005). This is important because it works to empower service users which can enhance the experience and outcomes of receiving care (Baines, 2011). 
Additional core tenets of AOP include understanding the intersectionality of oppression; engaging in a continuous process of critical reflection on self and practice; focusing on the struggles and needs of those who are oppressed and marginalized; and building allies with social causes and movements (Baines, 2007; Healy, 2005). Although critical to an AOP approach, I have selected not to draw fully on these core tenets because of the smaller scope of this study. These tenets are elements I would like to incorporate more fully in future research. While these tenets are important, they are not core to my work and the flexibility of an AOP approach allows me to focus on those tenets that I feel best reflect how I understand and approach this research.

This chapter detailed the theoretical framework used to guide this study by describing an AOP approach and explaining the tenets of AOP felt to be most relevant toward this research. Based on understanding existing literature about this topic through the lens of these tenets of AOP, I have been left to wonder what the stories of current or former CAF personnel can inform us about the experience of receiving mental health services within the CAF. I am also interested in knowing how these stories can be used to guide a discussion about whether and how AOP social work can contribute to or enhance current mental health services within the CAF. In the next chapter, I detail how these questions are answered by describing the methodology used to complete this study. 


\section{CHAPTER 3. METHODOLOGY}

This chapter details the methodology of this research project, which includes both the research approach initially intended as well as the actual methods used to complete the study. The chapter begins by describing narrative inquiry and details the reasons why this approach was selected. Following this, a description of the intended research approach is presented including the methods of recruitment, data collection and data analysis. The findings of attempting to conduct the research using this intended approach are detailed, specifically the challenges encountered when attempting to access the target population and recruit participants. These findings also explain why it was necessary to devise an alternative research approach in order to complete the study. Following this, the actual methods used in the study are described including the sample and methods of data collection and analysis.

\subsection{Narrative Inquiry}

Narrative inquiry is a research methodology that begins with experiences as expressed in the lived and told stories of individuals (Chase, 2003; Creswell, 2013; Fraser, 2004). Used in this way, narrative is understood as a spoken or written text giving an account of an event or series of events (Czarniawska, 2004, as cited in Creswell, 2013). It is based on the understanding that people communicate and reinterpret their life experiences through stories (Riessman, 2007). Narrative inquiry provides a way of gathering, investigating and analysing people's stories of experiences and events so as to reveal and interpret the meaning of those experiences (Chase, 2011; Riessman, 2007).

There is considerable variation in definitions of personal narrative among researchers, often based on discipline (Riessman, 2005). A narrative may be oral or written and can be elicited or heard during interviews, fieldwork or naturally occurring conversations (Chase, 2011). 
A narrative may be a short, topical story about a particular event organised around characters, setting and plot, an extended story about a significant aspect of an individual's life, or an entire life story from birth to present (Chase, 2011; Riessman, 2005). The types of data collected in narrative research are also diverse. Most commonly, data consists of first person, oral accounts of experience which may be found in archival documents such as letters and diaries, life stories collected in community settings, bounded segments of an interview, a brief story in response to a single question, or in-depth conversational interviews (Chase, 2011; Riessman, 2007).

The methods of analysis used in narrative research also vary significantly. All methods of analysis however, require the researcher to construct texts for further analysis which involves selecting and organizing documents, composing field notes or choosing sections of interview transcripts for close inspection (Riessman, 2005). Analysis also requires interpretation of narratives when they are used as data in social research as narratives "do not speak for themselves or have unanalysed merit" (Riessman, 2005, p. 2). There is no one single, correct way to do narrative analysis - in practice, different analytic approaches can be combined as they are not mutually exclusive and the boundaries between approaches are fuzzy (Chase, 2011; Riessman, 2005). Further, there are few studies where narrative researchers describe the pragmatic, step-by-step process they use to analyse their data.

Although various types of narrative research exist, generally the procedures for implementing it consist of focusing on studying a small number of individuals, gathering data through the collection of their stories and reporting individual experiences (Creswell, 2013). Ultimately, the narrative study tells the story of an individual's experiences, set within their personal, social, and historical context, and including the important themes in those lived experiences (Creswell, 2013). 


\subsection{Why Narrative Research?}

Because the focus of my research centres on uncovering what the stories of participants can inform us about their lived experience, a narrative approach is an appropriate methodology that may be best suited to answer my research question. This is because individuals often express their personal experiences in the form of stories (Chase, 2003). As the research question seeks to explore the personal experiences of current and former CAF members who have received mental health services within the $\mathrm{CAF}$, a narrative approach, with its focus on storytelling facilitates this process. This is discussed more fully below.

A narrative approach is also appropriate because of its coherence with both the topic and theoretical framework of this research which is demonstrated in a number of ways. First, the use of narrative centres the stories and voices of participants (Chase, 2003; Creswell, 2013; Fraser, 2004) which as previously mentioned, fits well with the focus of my research. The current lack of qualitative research related to this topic has left the voices of those with first-hand experience of the issue to go unheard. This has resulted in a lack of in-depth and detailed information commonly uncovered through the use of qualitative methods, thereby limiting the knowledge base surrounding this topic. The use of a narrative approach for this study assists in filling this gap in the literature. Further, narrative research is a relevant approach for the population of this study because it provides an opportunity for current and former CAF members to share their unique, individual stories. This is in contrast to military environments which require uniformity and where personnel are expected to conform to the larger group. A narrative approach to this study allows for the voices and unique experiences of each individual participant to contribute toward the knowledge base surrounding this research topic.

Second, a narrative approach is argued to be compatible with both the principles of AOP research and social work practice (Potts \& Brown, 2005; Riessman \& Quinney, 2005; Strier, 
2007). An important part of both narrative methods and social work practice is the focus on clients' stories and giving voice to marginalised groups through listening to their stories (Riessman \& Quinney, 2005). AOP encourages researchers and practitioners to open up discursive spaces in which individuals can develop their own interpretive story that gives meaning to their experiences (Dominelli, 2002). This works to validate and promote an individual's entitlement to explain their lives in their own ways thereby assisting in their empowerment, an important aim of AOP (Dominelli, 2002).

Additionally, AOP research acknowledges the power differences that are built into the research process and as such, researchers strive to design procedures and methodologies that are more egalitarian (Strier, 2007). Narrative based research incorporates such efforts because it is a methodology that creates a more equal exchange of power between the researcher and participant. By making participants' stories the central focus of the research and using them as the unit of analysis, narrative research positions the participant into the role of the expert and demonstrates a valuing of their lived experience as a legitimate form of knowledge. As the secondary aim of this study is to offer a preliminary discussion of the relevance of AOP for the CAF's mental health services, using a research approach that is compatible with the principles of AOP, including the importance of giving voice to clients, focusing on issues of power and valuing individuals' lived experiences, helps to centre and reinforce the importance of such principles. This then assists with the exploration of ways in which this practice approach can contribute to or enhance the military's current mental health services.

\subsection{Intended Research Approach}

The next sections of this chapter detail the research approach that was initially designed to complete this study. This includes the specific narrative approach that was selected as well as 
the methods of recruitment, data collection and data analysis. Following this, the findings that occurred after attempting to conduct the intended research approach are presented and used to explain why alternative methods were needed in order to complete the study. The actual approach used for this research is then detailed later in the chapter.

Intended narrative approach: "Restorying” (Clandinin\& Connelly, 2000).

When initially designing the methodology for this study, I selected to follow the narrative approach of "restorying" suggested by Clandinin and Connelly (2000). This approach was selected because it allows for an in-depth analysis of participants' stories which are organized chronologically and thematically in ways that meaning can be interpreted (Clandinin \& Connelly, 2000). This is a beneficial method of analysis for this study as participants' stories can be structured in ways that describe their experiences. Through restorying I would have been able to structure participant transcripts into a chronological sequence that would help to organize them in ways that interpretations and meanings of their experiences could be made. This sequencing would depend on the narratives shared by participants but could have involved restorying them into a chronological sequence with a beginning, middle and end. Further, this approach is also helpful toward identifying whether any of the themes that emerged from participants' stories are relevant toward the discussion of whether and how AOP social work can contribute to or enhance current mental health services within the CAF. Restorying can also involve organizing participant stories thematically and as such, I would have also looked for any themes that emerged within participants' stories, particularly those that could contribute to the discussion exploring the relevancy of AOP for the CAF's mental health services.

The approach begins with determining if the research question best fits a narrative approach (Clandinin \& Connelly, 2000). According to Creswell (2013), narrative research is best 
for capturing the detailed stories or life experiences of a single life or the lives of a small number of individuals. As my research question focuses on uncovering the experiences of a small number of current or former CAF members, specifically related to the context of receiving mental health services within the CAF, a narrative approach is appropriate. This is because, as mentioned above, individuals often express their personal experiences in the form of stories (Chase, 2003) and as such, a narrative approach with its focus on storytelling facilitates a process of exploring these individuals' personal experiences with the CAF's mental health services.

The next stage of this approach involves selecting individuals and spending time with them to gather their stories or life experiences, including information about the context of those stories (Clandinin \& Connelly, 2000). Stories would have been gathered by conducting individual semi-structured interviews. Interviews were selected because they are commonly the method of data collection used in narrative research due to their potential to collect in-depth and detailed information, to validate the knowledge of participants, to unearth hidden or subordinated ideas and to generate findings that resonate more with people's lives (Fraser, 2004). Interviews would have allowed current and former CAF members to share their individual stories of experience with the CAF's mental health services thereby allowing for an in-depth and individualized exploration, through those stories, to inform us about the experience of receiving these services.

The final stage of the approach suggested by Clandinin and Connelly (2000) involves analyzing participants' stories and then "restorying" them into a framework that makes sense. Restorying is the process of reorganizing the stories into some general type of framework (Creswell, 2013). For this study, this framework would have consisted of gathering stories, analyzing them for key elements of the story, and then rewriting the stories in a chronological 
sequence with a beginning, middle and end. Themes that arose from the stories would have also been detailed so as to provide a more in-depth discussion of the meaning of the story. In this way, data analysis would involve both a description of the story and the themes that emerged from it. The interview transcripts from current and former CAF members would have been restoryed chronologically and thematically as a way to help us "make sense" of those stories for understanding their experience of receiving the CAF's mental health services. Restorying thematically would have also assisted with identifying any themes relevant to AOP which would have been used to facilitate the discussion exploring whether and how AOP can contribute to or enhance the CAF's current mental health services.

\section{Intended method of recruitment.}

Although these methods of recruitment were conducted, I refer to them as intended because they did not achieve their purpose of securing participants for the study. This is discussed in more detail later in the chapter when describing the findings of the intended research approach.

For this study, I initially intended to interview up to five participants consisting of adults aged 18 and up and who were current or former members of the CAF that have received mental health services within the CAF from the year 2001 onwards. This timeframe was selected because the research seeks to explore more recent experiences with the CAF's mental health services, specifically services that have been delivered from the time that the CAF became involved with the Afghanistan mission.

Participants were recruited Canada wide by advertising a recruitment poster (see Appendix A) on the online social networking pages of campaigns related to the topic of military mental health including Military Minds Inc. and Send Up the Count. Other recruitment sources 
included branches of the Royal Canadian Legion and the Toronto and Ottawa Military Family Resource Centres.

A second phase of recruitment included having the recruitment poster distributed by sources including the Operational Stress Injury Social Support program and by peers within the MSW program who knew of individuals they felt may be interested or who knew of others who may be interested in participating in the study.

\section{Intended method of data collection.}

The intended method of data collection would have involved conducting up to five individual semi-structured interviews with participants. In narrative research, interviews are often conducted using a relatively informal and conversational style (Fraser, 2004). The use of an interview guide is sometimes suggested however, as a way to prepare for the wide range of stories that participants may tell and ensure that the general information of interest can still be gathered (Chase, 2003).

For this reason, I created an interview guide (see Appendix B) in which broad, openended questions would have been posed during the interviews. Participants would have been asked to share their experiences, stories and any other information they felt relevant. Probing questions would have also been asked when interested in exploring certain areas of a participant's story in more detail. Interviews would have been audio-recorded and hand written notes would have also been taken.

\section{Intended method of data analysis.}

The intended method of data analysis would have followed the restorying method suggested by Clandinin and Connelly (2000). This involves transcribing and coding each individual interview and then restorying participants' stories into a chronological sequence with 
a beginning, middle and an end. This would have been completed so as to structure the stories in a way that described participants' experiences receiving mental health services within the CAF. Following this, interviews would have been looked at together so as to identify broad categories and themes. Themes would be detailed as they relate to the discussion of whether and how AOP social work can contribute to or enhance the CAF's current mental health services.

These methods of recruitment, data collection and analysis were of particular relevance and importance to my research question, aim and population. Recruitment focused on reaching out to the target population, specifically current or former CAF members who had received mental health services within the CAF. Conducting individual semi-structured interviews as the method of data collection would have provided participants the opportunity to share their stories of experience with receiving the CAF's mental health services. These stories would have then been analysed by restorying them chronologically and thematically so that meaning could be made of their experiences with the CAF's mental health services and so that themes relevant to AOP could have been identified for the discussion exploring whether and how this practice approach can contribute to or enhance the CAF's current mental health services.

\subsection{Attempting the Intended Research Approach: Findings}

This section details the findings of attempting to conduct the research study as originally intended. The intended sample and method of data collection involved conducting up to five inperson interviews with current or former CAF members who have received mental health services within the CAF. There were many challenges that were encountered when trying to access the research population and recruit participants. Below I discuss those challenges and explain why it was necessary to devise an alternative methodology in order to complete this research project. 


\section{Recruitment challenges.}

After receiving ethics approval from the Ryerson University Research Ethics Board, I began recruitment on April 1, 2014. I started this process by contacting the recruitment sources described above to inquire whether they would support this research project by advertising or distributing my recruitment poster.

Two of the recruitment sources were online campaigns related to the cause of military mental health, specifically Military Minds Inc. and Send Up the Count. Both campaigns have an active presence on social networking sites and as such, I contacted the administrators of those sites to inquire whether they would allow me to advertise my research by uploading my recruitment poster onto their sites. I received a response from an administrator of the Military Minds Inc. site giving me permission to upload my recruitment poster. I did not receive a response from administrators of the Send Up the Count site.

At this time, I also began contacting various branches of the Royal Canadian Legion (RCL) to inquire whether they would be willing to advertise or distribute my recruitment poster to their members. In total, I contacted five RCL branches in the Greater Toronto Area. Of those five, I received two responses back. One stated that they would not be able to comply with my request while the other agreed to place my recruitment poster up within their building. I also contacted the RCL Ontario Provincial Command office to see if they would support the distribution of my recruitment poster by making it available more broadly to RCL branches across the province. I did not receive a response back.

I also contacted other potential recruitment sources including the Toronto Military Family Resource Centre and the Military Family Resource Centre - National Capital Region. Once again however, I did not receive a response back from either office. 
At this time nearly one month had passed since beginning my recruitment and I had not received any inquiries from interested participants. I discussed these concerns with my MRP supervisor and we agreed that I should attempt a second phase of recruitment. This involved identifying other possible recruitment sources and seeking permission from the Ryerson Research Ethics Board to contact them.

Once ethics approval was received, I began the second phase of recruitment. One of the additional recruitment sources identified was the Operational Stress Injury Social Support (OSISS) program. I contacted the National Program Manager of OSISS to inquire whether he would support the advertisement or distribution of my recruitment poster. He responded by explaining that because OSISS is a government program, they must follow government regulations with respect to research and that this involves a separate process for receiving approval. He agreed however, to put me in touch with the OSISS Regional Coordinator of Ontario who he stated could distribute my poster in a way that people who might be interested could contact me while at the same time maintaining a separation between the OSISS program and my research. I then contacted this individual and sent him my recruitment poster for distribution. During the second phase of recruitment, other students within the MSW program also offered to distribute my recruitment poster to individuals whom they knew personally and who might be or know of someone who might be interested in participating.

Despite these efforts, I did not receive any inquiries from interested participants. More than two months had passed since beginning recruitment and due to the time constraints of completing this MRP, I could not devote any more time to such efforts. The recruitment poster did however, continue to be advertised and distributed up until the final stages of writing this MRP in the hope that participants would still come forward before its completion. These 
recruitment sources were contacted during the final stages of writing the MRP to request that they remove the recruitment poster and discontinue its distribution. Recruitment was maintained as long as possible to the last practical moment of the MRP process but eventually needed to end because it would not have been ethical to continue recruiting past the point of being able to follow through with the research process if a participant came forward. After discussing with my MRP supervisor, we agreed that it was time to devise an alternative approach to my research the details of which are presented below.

\section{Addendum.}

While writing the final chapter of this MRP, I received an inquiry from an interested participant. This individual was informed that I was currently in the final stages of completing the study and as such, it was too late to include him. I offered to still speak with him and hear his story but explained that nothing we discussed could be used in the study. He understood this and indicated that he still wanted to speak with me and share his story despite it not being used for the purpose of this research. Nothing from the conversation had with this individual was used as part of this MRP.

\subsection{Actual Research Approach}

This section outlines the process undertaken to complete this research project after determining that the intended approach would not be possible. The section begins with a description of thematic narrative analysis which is the actual method used for this research project. The method of data collection and the study's sample are then detailed. This consisted of finding sources of public media in which interviews were conducted with the target sample, specifically, current or former CAF members who have received mental health services within 
the CAF. Finally, a description of the specific process used to complete a thematic narrative analysis of the data for this research is provided.

\section{Actual narrative approach: Thematic narrative analysis.}

For this research project, I used thematic narrative analysis to examine and interpret the stories of current and former CAF members' experiences receiving mental health services within the CAF. Thematic analysis places emphasis on the content of a text - "what" is said, written, or visually shown - as opposed to "how", "to whom," or "for what purpose" it is told (Riessman, $2007 ; 2005)$. This focus on the content of stories is well suited for this research as the study is concerned with “what" participants' stories reveal. In this method of analysis, researchers collect many stories and inductively create conceptual groupings or themes from the data (Riessman, 2005).

Although the stories being analysed for this research were not elicited by conducting inperson interviews directly with participants, the use of thematic narrative analysis is still appropriate. Researchers using a thematic narrative approach are typically not concerned with how a story unfolds in a conversational exchange or the questioner's role in constituting it - the conditions of production of a narrative (Reissman, 2007). As previously mentioned, a thematic approach is concerned with the content of a narrative. As such, thematic analysis is suited for a wide range of narrative texts and can be applied to stories found not only in interview conversations but also in written documents (Reissman, 2007). Media sources are often used for other approaches to research (e.g., textual analysis, discourse analysis), but I did not want to switch to these approaches because they often do not focus on the actual story and lived experiences of participants. Instead these approaches focus on broader social and structural themes (Johnstone, 2008) which are not the intent of my research. Further, thematic analysis is 
the usual approach for working with archival documents (Riessman, 2007) making it an appropriate method for the type of narrative text used in this research, which is described in more detail below, in the form of written interviews collected from newspapers and other media sources.

Thematic narrative analysis is most often confused with grounded theory. There are however, important methodological differences. Briefly, in grounded theory prior concepts have no place in the analytic process, segments of data are taken apart and named, little attention is given to sequencing, and the main objective is to develop a theory that can be generalized across cases (Creswell, 2013; Riessman, 2005). Conversely, in thematic narrative analysis, prior theory and research guides the inquiry process, sequencing is preserved so as to keep the story intact, context is attended to, and analysis is case centred and does not seek to theorise across cases (Riessman, 2005; 2007). This study does not seek to develop a theory or explanation about an experience that can be generalized across cases which is the main objective in grounded theory. Instead it aims to explore what the themes emerging within each individual participant's story can inform us about their experience, as the "what" of their story rather than the "how" or "why" of their story and as such, thematic narrative analysis is the best approach.

Using narrative inquiry to gather and examine the stories of current and former members of the Canadian military who have received mental health services within the CAF is not only important from an AOP theoretical perspective as previously discussed, but is also a useful method for understanding their lived experiences and for exploring the potential of AOP social work within the CAF's mental health services. This research uses these stories to examine what the experience of receiving mental health services within the CAF is like by highlighting the range of circumstances encountered by participants. In doing so, these stories also provide 
insight for a preliminary discussion on how AOP social work can enhance the CAF's current mental health services.

\section{Actual method of data collection.}

Although the interview is an important way to collect data in narrative research, it is not the only way (Chase, 2011). How information is collected depends on a number of factors. Some choices are made not because they provide the best fit but because many constraints on the ideal research situation exist. Ultimately, when faced with constraints, each individual project design rests with the researcher who seeks to make the best use of all resources available within an ethical framework (Bold, 2012). This may be particularly necessary for researchers conducting studies with vulnerable or hard-to-reach populations where a single, interviewing method may not be possible (Liamputtong, 2007). In such instances, researchers may instead require more flexible investigative methods (Liamputtong, 2007). In my case, difficulties arose when trying to access and recruit participants and as such, I was required to devise an alternative method of data collection.

When thinking about an alternative method of data collection, it was important to consider the practicalities of this research project given the time constraints involved with any MRP, and not wanting to completely change my topic, theoretical framework or methodology. As the topic of my research has been a prevalent issue covered in the media over recent years, I chose to collect data from any public media sources where current or former CAF members talked about their experiences with mental health. Sources of public media seemed to be the second best choice of data because I was more likely to find interviews where the voices of my target population were directly elicited. This is as opposed to relying on other sources of data where participant voices may not be included (e.g., policy documents). In this way, the use of 
media sources allowed me to stay true to a narrative approach which focuses on centring the voices of participants (Chase, 2003; Creswell, 2013; Fraser, 2004). I sought to explore more recent experiences with the CAF's mental health services due to Canada's involvement with the mission in Afghanistan and the link between combat exposure and mental health. As such, I searched for media sources released from the time that the CAF first became involved in Afghanistan, specifically from the year 2001 onwards.

Data was searched within national Canadian media outlets including the Canadian Broadcasting Corporation (CBC), CTV, Global News, and The Chronicle Herald. An online search was undertaken for sources of public media such as newspaper articles and television news stories that covered topics related to my research question. The search was then narrowed to those sources where interviews were conducted with current or former CAF members who spoke about their experiences receiving mental health services within the CAF. These media sources became the narrative unit for my research, which in a thematic narrative approach, can consist of bounded written segments of text about a life event or experience (Riessman, 2007).

The results of this search were one newspaper article, two news articles retrieved online and one news series. The first source was a newspaper article, titled "Veteran urges upgrade of mental-health services available to Canadian Forces personnel" (Lightstone, 2014) published in The Chronicle Herald. The second source was a news article, titled "Soldiers with severe PTSD have trouble finding help" (Elliott, 2010) and was retrieved online from the CBC website. The third source was a news article, titled "Canadian soldiers fight mental-health stigma" (Pellicer, 2013) and was retrieved online from the CBC website. The final source was a televised news series titled, "Invisible Wounds" (Loney, 2014) and was retrieved online from the Global News website. 


\section{Sample.}

Within the data sources collected, a total of seven current or former CAF members are interviewed about their experiences receiving mental health services within the CAF. These seven individuals compose the sample used for this research. Details about these individuals and their stories are provided in the next chapter.

As participants were drawn from public media sources, they are referred to in this MRP by the names used in their interviews. The story of the first participant, Tim Boyce, comes from the article published in The Chronicle Herald titled "Veteran urges upgrade of mental-health services available to Canadian Forces personnel" (Lightstone, 2014). The stories of participants Shawn Hearn and Joanne Curnew come from the article published by the CBC titled "Soldiers with severe PTSD have trouble finding help" (Elliott, 2010). The story of Gerry Corbin comes from the article published by the $\mathrm{CBC}$ titled "Canadian soldiers fight mental health stigma" (Pellicer, 2013). Finally, the stories for the Unnamed Sergeant, Captain Wayne Johnston and Corporal Malcolm Williams come from the news series titled "Invisible Wounds" (Loney, 2014) which aired on Global News.

\section{Actual method of data analysis.}

The process of thematic narrative analysis used for this research first involved creating a way to organize the data collected from the media sources. A chart was developed (see Appendix C) consisting of three columns - name of participant, transcription, and memos. Information about the media source from which the data was retrieved was also documented on the chart including the title of the article and the date it was published.

The next stage of analysis involved examining each individual article line-by-line. Those lines in the article that were felt to construct the participant's narrative were then placed into the 
transcription column of the chart. This included lines from the article that are direct quotes from the participant (identifiable by the use of quotation marks in the transcription column) and the indirect content of the news reports such as the summary statements of the reporter about the content of a participant's story (identifiable by the lack of quotation marks in the transcription column and the use of parentheses in the name of participant column).

Lines of indirect content were used because they provide information about a participant's story that helps to construct a narrative account of their experience. Here again, it is important to note that with thematic narrative analysis, emphasis is on "the told" - the events and cognitions to which language refers or the content of speech (Reissman, 2007). Although certain lines from the articles are not the direct, spoken words of participants, they formulate what was told during the course of the interview making them important toward understanding the content of a participant's narrative.

Once a transcription of each participant's narrative was organized into the chart, the second stage of analysis began. This involved deeper immersion into each individual transcription using the same line-by-line method. Lines that were felt to be relevant toward the research question, specifically those that described the experience of receiving mental health services within the CAF, were highlighted and given a code. As much as possible, in-vivo codes were used so as to retain the words used directly by participants. The use of in-vivo coding is valuable in narrative research as it provides a way of keeping stories intact by using the actual words or phrases of the narrator (Fraser, 2004). I further chose to use in-vivo codes in an effort to more fully surface the voices of participants given that direct interviews were not conducted.

The third stage of analysis involved looking for any themes that emerged within each individual participant's story. In thematic narrative analysis, each participant's story is an 
individual case where the themes emerging within that story represent the within-case findings (Riessman, 2007). The codes within each participant's transcript were observed for consistencies and if identified, grouped together into a theme. This approach is consistent with thematic narrative analysis which generally involves creating conceptual groupings or themes from the data (Riessman, 2005). Although line-by-line coding was used, thematic understandings were only developed within the context of the whole story of each participant. This was done to maintain the integrity of thematic narrative analysis and to distinguish from a grounded theory approach (Riessman, 2007).

Although a distinguishing feature of narrative analysis is that it is case centered (Reissman, 2007) the thematic approach is useful for theorizing across a number of cases finding common thematic elements across research participants and the events they report (Riessman, 2005). As such, the final stage of analysis involved looking for any patterns that emerged across participants' stories. In doing so however, the themes within each story were kept intact when compared to the other stories so as not to develop across-case themes. Instead, patterns between the themes of each story, specifically whether any similarities or differences emerged, were explored. The findings of this process of thematic narrative analysis are presented in the next chapter. 


\section{CHAPTER 4. FINDINGS}

This chapter presents the findings of data analysis by detailing the themes that emerged within participants' stories as well as the similarities and differences found across stories. While these findings may be limited, they represent what was available from the narrative units analysed. In some of the narrative accounts, the emergent themes are limited in both number and depth. This is because I used pre-existing data and thus could not probe for more details. Although the findings are limited they are still important because they present the voices and experiences of these current and former CAF members. Their stories provide insight about what it is like to receive mental health services within the CAF offering findings that emerge from their unique perspective. This is an approach that other studies have failed to undertake making these findings distinct from what has previously been uncovered.

Each participant's story is presented as an individual case with the themes that emerged (referred to as the "within-case findings"). At the beginning of each case, a brief summary of the participant and their story is provided. Segments of text (single spaced and indented) are used to highlight the content of the themes found within a participant's story. Following the within-case findings, the similarities and differences in themes found across cases (referred to as the "acrosscase findings") are presented.

\subsection{Within-Case Findings}

\section{Tim Boyce}

Tim Boyce is a 46-year-old army sergeant and former infantry instructor from Montreal, Quebec. He lives alone at Canadian Forces Base 12 Wing Shearwater in Halifax, Nova Scotia and has served with the CAF in Syria (2005), Kosovo (2000), Bosnia (1998), and Croatia (199394). In 2006, he was diagnosed with several emotional problems including PTSD. Tim has said 
that his war-zone experience is what led to his PTSD and that his quality of life in recent years has been dismal. He has attempted suicide on more than one occasion and has personally known four military comrades who have taken their own lives. He says that he lives in a home with blacked-out windows and cannot tolerate confined spaces or crowds. He says he is incapable of maintaining close relationships with family and friends and that his marriage has dissolved. He has also struggled with addictions. Tim was medically released from the military at the end of March 2014.

A first theme identified within Tim's story is difficulties with mental health system. Within Tim's story, he discusses the difficult experiences he has had with the military's mental health system:

His journey through the military's mental health system has been extremely challenging at best, exacerbating at worst.

Parts of the difficulties for Tim were the interactions he had with service providers:

He has consulted dozens of medical professionals in the Forces and in the civilian mental-health system. Some were very caring, but many others, he said, "didn't do their jobs" and he fell through the cracks.

Another theme that emerged within Tim's story is "someone can try to fix things." This theme relates to his feelings that changes are needed to the military's mental health system. He is speaking out because:

In his view, the system needs to be reformed to assist current Armed Forces personnel and recruits starting their careers, should they need mental-health help.

He states:

"No, it's not all bad. But the bad situations (in the mental-health system) outweigh the good ones." 
Although his experience through the military's mental health system was difficult, Tim hopes that something can be learned from it so that improvements can be made for others. He states:

"It's too late for me. But maybe, just maybe, someone can learn from this and try to fix things so others don't ever have to go through this."

\section{The Unnamed Sergeant}

The sergeant has served in the CAF for more than 17 years with multiple tours in Afghanistan. After returning to Canada in 2008, his life began to spiral out of control as he tried to cope with his mental health. The sergeant lost his children and his marriage, and he fell into bankruptcy. On three different occasions, he contemplated suicide. He was recently diagnosed with PTSD.

One theme that emerged within the unnamed sergeant's story is "turn a blind eye." This theme relates to a lack of empathy and support for soldiers struggling with their mental health particularly from those higher in the chain of command. He states:

"When you're over there, when you're at the ramp ceremonies, loading coffins into the planes, it takes its toll on you, especially when you're close to these people. Now we're back in Canada and it's still going on. I just feel that a lot of the higher ups turn a blind eye to it."

The sergeant also describes a situation that demonstrates a lack of empathy from a commanding officer:

"I have a good friend that was over on tour with his sergeant major and his sergeant major said, 'We were on the same tour, I'm fine - so what's wrong with you?'”

This theme also appeared when he discusses the difference in view of physical versus mental injuries:

With a physical injury comes a degree of understanding - you can see it, its severity, if it has healed. But a mental injury - hidden from sight - can be dismissed, ignored and misunderstood. 
This theme also emerged when the sergeant discusses his experience receiving mental health services. These services seem to be blind to the long term impact of mental health diagnoses such as PTSD as they are brief and focus on completion so as to return personnel back to military service. He states:

"They treat you as quickly as they can and you're back out the door."

Another theme that emerged within the unnamed sergeant's story is difficulty accessing mental health services. The sergeant speaks about a number of challenges he encountered when trying to make appointments with CAF mental health professionals which involved:

A cycle of preliminary appointments with half a dozen different medical officers, multiple requests for referrals, visits with social workers, and months and months of waiting.

When attempting to access mental health services on another occasion, the sergeant encountered similar difficulties:

When he tried to book another appointment with a mental health professional, to address issues he says he hadn't really dealt with yet, he was told he needed another referral, which delayed the process by another few months.

The sergeant also speaks about the desperate measures that he had to take in order to access mental health services in a timely manner. His story details one situation that demonstrates this:

There are four basic questions. "Are you suicidal?" He answered no. "Do you have plans to be?" No. "Are you homicidal?" - "Yes I am," he told them. "Do you have a plan?" "Yes, I've got a lot of guns." He wasn't actually homicidal - he was desperate to get help. And he says he had his appointment to see a psychologist and psychiatrist the next day.

Another theme that emerged within the unnamed sergeant's story is need for advocacy. This theme refers to a need for advocacy for military personnel struggling with issues of mental health. He states:

"You need somebody there to advocate for you." 
His story describes the way in which he was advocated for:

He credits a medical officer on base for helping him. She pushed to get him help and told his command officer that he needed to "back off" the sergeant before he was pushed too far.

A final theme that emerged within the unnamed sergeant's story is "fear the repercussions."

This theme concerns how fear acts as a barrier to seeking mental health services. The sergeant comments that fear is stopping a lot of CAF members from speaking up about their mental health and seeking help. He states:

"People aren't going to talk to you because they fear the repercussions." This fear, he says, is also stopping a lot of people from seeking help from mental health professionals.

The sergeant's story speaks to the reality that for some, it is the fear of losing their job:

Coming forward with mental health issues can have career implications, and many soldiers who were planning on a long military career are afraid they will find themselves suddenly unemployed with a very specific skill set.

The sergeant also explains that:

Others fear the stigma surrounding mental health.

\section{Shawn Hearn}

Shawn Hearn is a native of St. John's, Newfoundland who served as a sniper in the Canadian military during the Bosnia mission in 1994. He says he came back from Bosnia a different person and by 1997 he was hospitalized following an overdose. He was diagnosed with PTSD in 2000. He then left the military and began trying to understand his diagnosis which included symptoms such as severe depression, night fears and flashbacks. Over the intervening years, Shawn found some recovery through a combination of counselling and medication. He also helped create a national system of peer support called OSISS - the Operational Stress Injury Social Support program. Despite his apparent recovery, Shawn's unresolved trauma began to surface once again. In January 2010, he wound up in the psychiatric ward of a hospital. His stay 
was short even though he told the doctors who discharged him he was not well. Discharged and left to his own devices, Shawn attempted to take his own life. It was then that his peers at OSISS and his case manager at Veterans Affairs started making some calls to get him into a treatment program. Shawn was admitted to Homewood Health Centre, a private facility in Guelph, Ontario for a six-week treatment program for PTSD.

A theme that emerged in Shawn's story is PTSD symptom severity as a barrier to accessing care. This theme refers to the difficulties he encountered when attempting to access mental health services. Shawn's story speaks of the drastic circumstances he experienced before finally being able to access the mental health services he needed. His story shows how the severity of his PTSD symptoms acted as a barrier to accessing care:

For those soldiers who suffer from the most severe form of post-traumatic stress disorder, there are still serious gaps in the system of care.

Shawn's difficulty accessing care was due in part to the strict admissions criteria of some treatment programs:

Many treatment programs will exclude a patient who has any anger problems, who may have developed an addiction, or who recently attempted suicide - all of which are common among veterans suffering with PTSD. The criteria may be there to protect other patients and ensure program success. But the result is that the programs screen out people - like Shawn - who most need help.

Another theme that emerged within Shawn's story is necessity of advocacy. This theme concerns the need for advocacy in order to access mental health services. Shawn is speaking out because:

He knows he was lucky and had strong advocates who got him into the system. He's worried about those who may not get the chance to feel better.

He states:

"Yes, I was sick, but I was still able to articulate what was happening to me. For the average soldier or veteran some of these folks are unaware what's happening to them. These individuals are unable to advocate for themselves." 


\section{Joanne Curnew}

Joanne Curnew is a veteran of the CAF who developed severe PTSD after serving in places such as Haiti and Alert, Nunavut. In late 2009, Joanne's mental health took a turn for the worst. She was admitted to an in-patient PTSD treatment program run by Veteran's Affairs at Ste. Anne's Hospital in Ste. Anne de Bellevue, Quebec.

A first theme that emerged within Joanne's story is challenges getting admitted into

program. This theme refers to the difficulties she encountered when attempting to access mental health services. She speaks about the challenges she encountered when trying to get admitted into the PTSD treatment program at Ste. Anne's Hospital which included the amount of information they required:

"They interviewed, they requested so much paperwork and so many documents, your medical, your reports from your psychologist, psychiatrist. They dug into every little detail they could possibly think of."

Another difficulty was the long wait time:

It took three months of back and forth before Joanne was finally admitted to the program at Ste. Anne's. During those long months, she continued to spiral downwards.

Joanne speaks about the stress she experienced while waiting:

"It was extremely difficult I even reached the point where I was thinking suicidal thoughts. Every time the phone rang, you hoped it was Ste. Anne's, you hoped you'd met the criteria and were going to be a patient there. It put a lot of strain on me, as well as my marriage, and my home life. I isolated so bad I very rarely went out my door.”

Within her story, we also learn about the strict admission criteria of the program:

At Ste. Anne's, soldiers can be refused admission, for example, if they are not stable, cannot manage their medication, recently attempted suicide, have other medical or psychiatric problems, have substance abuse problems, or anger management problems. 
Another theme that emerged within Joanne's story is changes needed to program. This theme refers to her feelings that changes are needed to the PTSD treatment program at Ste. Anne's. Necessary changes include a more timely admissions process:

She's worried about the future of the program at Ste. Anne's if it can't admit more people into care more quickly.

She states:

"We have troops over in Afghanistan that are coming back with PTSD that need help and have to wait around for six to eight months or 10 months to get it. That's a sin. That's a real sin. And the problem's not going to go away."

Joanne also notes that she would like to see the program fill all of its available treatment beds:

"It's a shame in a way because they have a 10-bed floor that I was the only patient on for all three weeks. At the end there was only two of us in the whole class."

\section{Corporal Malcolm Williams}

Cpl. Malcolm Williams deployed to Afghanistan in 2006. During that deployment, he drove over an improvised explosive device which left him with both physical and mental injuries. He was diagnosed with PTSD while still in Afghanistan. Once back in Canada, he was prescribed medications to treat his constant pain, to which he became addicted. His PTSD symptoms which included flashbacks, disassociation, and anxiety became too much to bear and he attempted to take his own life. Following this suicide attempt, he was admitted to Homewood Health Centre where he spent three months receiving treatment for his PTSD. He was medically released from the military in February 2014.

A theme that emerged within Cpl. Williams' story is 'it's kind of like you have a

disease." This theme concerns mental health stigma in the military. He states:

"If you mention it on base that you have PTSD, it's kind of like you have a disease." 
He speaks about what his experience was like at work:

"I was going to work and nobody would talk to me. I would just go to my cage and nobody would really talk to me. It was like I had a disease or something."

Cpl. Williams' story also speaks to the isolation that those struggling with issues of mental health can experience within the military:

Soldiers with PTSD could be taken out of their unit and put in a separate unit designed to help them with their disorder, but to Cpl. Williams, it was another form of isolation.

He states:

"They handle you so that you're not amongst the unsick."

Another theme that emerged within Cpl. Williams' story is multiple barriers to accessing mental health services. This theme relates to the multiple barriers he encountered when attempting to access the military's mental health services. Cpl. Williams notes that for him, part of the difficulty involved seeking services even when they were available. In his story he shares that when he had appointments with psychologists he did not always go because he did not like to talk about Afghanistan or his personal problems. He states:

"Just bringing it up would always cause anxiety. And I was always having anxiety, so going to those appointments and talking about my Afghan experiences that would just increase the anxiety even more."

This theme also appears within Cpl. Williams' story when he speaks about the gap in mental health services he experienced after moving. He states:

"They offered me a professional at first, when I first got PTSD. And then when I moved from Edmonton to St. Catharines, there was about a year where I didn't have one. Because I had just moved to the area. It was supposed to be all set up but it wasn't. So for a full year I didn't see a doctor."

According to Cpl. Williams:

He was put on a waiting list and that's why he wasn't able to see a doctor. 
Cpl. Williams also speaks about the drastic circumstances that occurred before he began to receive the type of services he needed further highlighting the theme of difficulty accessing mental health services. Within his story we learn that following his suicide attempt:

His wife called the military demanding help for him. Cpl. Williams said she didn't think he was receiving adequate help from his doctor and threatened to sue.

He states:

"And then when she said that, that's when they really started to take care of me." Another theme that emerged within Cpl. Williams' story is positive benefits of receiving mental health services. This theme refers to the positive benefits he experienced once he began receiving mental health services. Cpl. Williams shares that he spent three months at Homewood Health Centre and that while there:

He was treated for his addiction and PTSD symptoms, including learning exercises and breathing techniques to help with his flashbacks.

He states:

"My time in Homewood was positive because it got me clean again and it got me thinking straight again."

\section{Captain Wayne Johnston}

Cpt. Wayne Johnston is 56-years-old and has served in the CAF for 41 years. Beginning in 2008, Johnston served as the national repatriation officer, helping the families of Forces members killed or severely wounded in action. He was diagnosed with PTSD in 2010. He was medically released from the military in April 2014.

A theme that emerged within Cpt. Johnston's story is mental health stigma. We hear about his experience with mental health stigma in his story:

More than the headaches, the sleepless nights and panic, Capt. Johnston says the most painful part of his diagnosis is the stigma. 
He states:

"It gets your soul, it scorches it."

Capt. Johnston's story speaks about the need to address mental health stigma in order for military personnel to seek help:

There are pills and mental health professionals that can help manage PTSD, but at the end of the day, people still need to stick their hand up and say "I need help." The only way that will happen, he says, is to end the stigma surrounding mental health.

\section{Gerry Corbin}

Gerry Corbin is a veteran living with PTSD who served in the Canadian military for 28 years. Corbin is the former regional representative for Veterans UN-NATO Canada, an association that helps veterans find resources such as mental health services.

A theme that emerged in Gerry's story is "you get tagged in the service." This theme relates to the career implications that seeking mental health services can have on military personnel. He explains how this acts as a barrier:

"Once you go through the process of admitting you have PTSD and you start getting these resources, you get tagged in the service, you get put in a medical category. That means no promotion, no posting, no nothing - and once you're tagged, that will follow you for the rest of your career."

Another theme that emerged in Gerry's story is "have to push to get those appointments." This theme relates to the difficulties he encountered when attempting to access mental health services. We learn about his experience through his story:

He is receiving treatment with a psychologist and psychiatrist at two veterans' hospitals, though he says it takes a lot of initiative to make sure he receives treatment.

He states:

"Once you get into the system the treatments are there... but you have to push to get those appointments." 
The findings presented above represent the themes found within-cases. Within each individual participant's story, distinct themes emerged based on their experiences with the CAF's mental health services. These themes help to highlight the unique circumstances experienced by each participant. The next section details the across-case findings in which the similarities and differences among participants' themes are analyzed.

\subsection{Across-Case Findings}

\section{Similarities in Themes Across-Cases}

An across-case analysis found certain similarities among the themes that emerged within participants' stories. Across-case analysis involved looking at the themes that emerged within each participant's story and comparing them to the themes found within other participants' stories. This was with the aim of identifying whether any similarities or differences existed among the themes. Similarities found across-cases include difficulties accessing mental health services, desperate circumstances occurring before receiving needed care, experiences of mental health stigma, fears related to disclosing a mental health issue and opinions that changes are needed to the CAF's mental health system, each of which is discussed below.

When looking at the themes that emerged within each participant's story, a common experience was difficulties accessing mental health services. This experience is present in the

themes of six of seven participant stories. Some of the difficulties that participants encountered when attempting to access the military's mental health services show similarities and include having to attend multiple appointments with different service providers, needing to provide numerous documents of health and other personal information, requiring several referrals, enduring long wait times and having to meet the strict admissions criteria of treatment programs. 
Another similarity found across-cases are desperate circumstances occurring before receiving needed care. These desperate circumstances were necessary in order to access the military's mental health services in a timely manner. Two participants spoke about the drastic measures it took before being able to access the mental health services they needed. These measures included a suicide attempt and threat to sue as well as having to falsely disclose the intention to commit homicide. The experiences of these two participants demonstrate similarities found within the theme of difficulty accessing mental health services across-cases.

Another similarity found across-cases can be seen among themes related to mental health stigma. Participants spoke about the stigma that can surround military personnel affected by issues of mental health. This includes the ways in which those with a mental health diagnosis can be treated differently and isolated from the rest of the group as well as how stigma can act as a barrier to seeking mental health services. Some participants also spoke about the need to challenge mental health stigma within the military in order for situations to improve.

Themes of fear related to disclosing a mental health issue were also found to be a similarity across cases. A number of participants' stories had themes in which fear was present. Some participants spoke about fear acting as a barrier to seeking help. Others spoke about the fear of possible career implications if a mental health issue was disclosed while others spoke about the fear of being stigmatized.

A final similarity found across-cases can be seen in themes related to opinions that changes are needed to military mental health services. Certain participants noted that they were sharing their story in hopes that others could learn from their experience and so that the mental health system within the military could be improved. Some of the changes that participants 
mentioned they would like to see include reducing lengthy wait times and ensuring that all available beds in treatment programs are filled.

\section{Differences in Themes Across-Cases}

Across-case analysis also found certain differences among the themes that emerged within participants' stories. For one participant, a theme related to the lack of empathy from military personnel higher in the chain of command and from mental health service providers was unique. This was not a theme that emerged within any other participant's story.

Another theme that only emerged within a single participant's story was positive benefits of receiving mental health services. This participant's story shows that once he was receiving the type of mental health support he needed, that he experienced positive benefits toward his wellbeing. His was the only story in which the positive benefits of receiving mental health services emerged as a theme. After considering the within and across-case findings, a more thorough discussion of the research outcomes are detailed in the next chapter. 


\section{CHAPTER 5. DISCUSSION}

This chapter presents a discussion of both the research outcomes of this study and the process involved in its completion. Discussion centres on the ways in which the study's outcomes answer the research question, specifically, what the stories of current and former CAF personnel can inform us about the experience of receiving mental health services within the CAF. Also included is a preliminary discussion of the secondary aim of this research, that is, exploring whether and how AOP social work can contribute to or enhance the CAF's current mental health services.

The chapter begins with a discussion of my interpretations of the research outcomes specifically as they relate to the theoretical framework, methodology, and literature that guide the project. Also detailed is a discussion of the research process that occurred while completing this study and my interpretations as to why the project unfolded as it did. Following this, the limitations and authenticity of this research project are presented. Finally, the chapter ends with a discussion on the implications of this research project for social work as well as recommendations for future research related to this topic.

\subsection{Interpretation of Research Outcomes}

The outcomes of this study can be interpreted in ways that relate to the theoretical framework guiding this project which is composed of certain tenets of AOP. When reviewing the research outcomes, a number of links to these tenets emerge. One such link relates to the AOP tenet of focusing on the ways in which oppressive forces create and affect the social problems people experience (Mullaly, 2002). Here, oppressive forces refer to those societal conditions that negatively impact on individuals or groups belonging to particular social categories (e.g., sexism for women, racism for racialized people). Resulting from these oppressive forces are unjust 
treatment and circumstances such as discrimination, marginalization and harmful stereotypes. These conditions cause and contribute to the social problems people experience in their everyday lives. For this study, I was particularly interested in learning whether sanism as a form of oppression would emerge in any of the stories shared by participants. Sanism describes the systematic subjugation of people who have received mental health diagnoses or treatment (Poole et al., 2012). As with other forms of oppression, sanism may result in discrimination or other negative circumstances but specifically for those affected by issues of mental health.

My interpretation of the research findings is that for certain participants, sanism as a form of oppression was experienced. Experiences of sanism were identified specifically in the form of mental health stigma which is a theme that emerged within certain participants' stories. These participants spoke about the experience and impact of mental health stigma in the military and shared about not wanting to disclose a mental health diagnosis for fear of being stigmatized, treated differently, or isolated from others. Some participants also expressed that stigma acts as a barrier for military personnel to seek mental health services. The experience of mental health stigma has also been found by other studies related to military mental health (Castro et al., 2004; Pietrzak et al., 2009).

The experience of mental health stigma is prevalent for example in one participant's story when he shares that he felt as though he had a disease due to the ways in which he was treated after being diagnosed with PTSD. Within his story he also speaks about how those in the military with a mental health diagnosis can be perceived as weak.

This is significant because it is these types of perceptions that can contribute to or reproduce the negative stigma surrounding issues of mental health. These types of perceptions and the stigma that results can be linked to the use of medicalized perspectives and approaches 
toward mental health where individuals are labelled and pathologized (Larson, 2008). The acts of labelling and pathologizing are forms of sanism where the former ascribes a marker that is used to identify and distinguish an individual with a mental health diagnosis while the latter involves regarding or treating someone as psychologically abnormal or unhealthy. In both cases, this is problematic as they contribute to the often negative and unfair views or treatment of those affected by issues of mental health. Alternative understandings and approaches to mental health that counter sanism are both important and helpful because they challenge and resist these perspectives that cause harm. Recognizing sanism and the impact of stigma in the experiences of military personnel reinforces the need for the CAF to continue addressing and challenging these negative perceptions so as to reduce the harm that can be experienced by those military personnel affected by issues of mental health.

Another way which the research outcomes can be interpreted as they relate to the tenets of AOP guiding this study is by looking for ways in which the findings link to the impact of power dynamics in service delivery (Mullaly, 2002). This involves being aware of the relationship between service providers and service users. Commonly in such relationships, those providing a service are placed in a position of greater power than those receiving it as they are the ones viewed as the expert. AOP however, encourages a more equal sharing of power in which service providers facilitate conditions by which service users can take control of their own circumstances and participate fully in all aspects of service delivery (Baines, 2011; Dominelli, 2002). Although the research outcomes do not speak directly to the impact of power dynamics within the delivery of mental health services, I would interpret that issues of power do still emerge within some participants' stories. 
This can be seen in one participant's story when he shares his feelings about a lack of empathy for military personnel affected by issues of mental health from those positioned higher in the chain of command. He shares that in his experience commanding officers can ignore or not take seriously the circumstances of military personnel struggling with issues of mental health. This speaks to issues of power as it is those higher in the chain of command who are responsible for the welfare of lower ranking members.

A lack of empathy for the mental well-being of military personnel from those higher in the chain of command - and who therefore hold positions of power - can have significant repercussions. Such situations may inhibit or prevent personnel from coming forward and disclosing a mental health issue or from seeking needed services. A lack of empathy may also mean that attitudinal and structural changes to the way mental health is approached in the military may not be effected as it is those higher in the chain of command that hold the position and authority to do so. Studies related to military mental health have not explored how these issues of power may impact on individuals affected by a mental health issue or on the delivery of military mental health services. However, an AOP perspective allows for a greater understanding of the impact of these types of power dynamics (Dominelli, 2002) making it possible to see how issues of power within the military can affect those struggling with their mental health and mental health services.

Another way in which the outcomes of this study can be interpreted, is in the way they relate to the final tenet of AOP guiding the research, which is the view that people are experts of their own lives (Dominelli, 2002). This tenet refers to valuing the knowledge of those with lived experience of an issue (Baines, 2011; Dominelli, 2002). The research outcomes relate to this tenet of AOP through the use of narrative inquiry as the research methodology for this project. 
Despite not interviewing participants directly, efforts were undertaken to centre the voices of current and former CAF members as much as possible in the research. Data collection involved purposefully searching for media sources where interviews with current and former CAF members occurred. In this way, it was the voices of participants that composed the story of their experiences which is central to a narrative approach (Riessman, 2007).

The research outcomes also relate to a narrative methodology as the themes that emerged came from analysing the stories shared by participants. Using participants' stories as research data places them in the position of being the expert as it values their experiences as a legitimate source of knowledge. This is consistent with an AOP approach which encourages that knowledge be constructed by those with lived experience of an issue (Potts \& Brown, 2005). As much as possible, these themes were developed through the use of in-vivo coding so as to maintain the words used by participants themselves. Segments of text that are direct quotations from participants were also taken from the interviews and presented in the findings so as to further allow their voices to be heard in the research outcomes. Doing so works to further value the knowledge and expertise of those about whom the research concerns (Dominelli, 2002).

\subsection{Comparison of Research Outcomes to Other Study Findings}

Interpretations of the research outcomes can also be made as they relate to the findings of other studies concerned with the topic of military mental health. Specifically, certain similarities and differences can be observed between the findings of this research and those of the existing literature.

Themes that emerged within most participants' stories relate to the difficulties encountered when attempting to access military mental health services. This is also a theme that exists within the existing literature related to military mental health (Castro et al., 2004; 
Drapalski et al., 2008; Kim et al., 2011; Pietrzak et al., 2009; Stecker, Fortney \& Sherbourne, 2011; Sudom, Zamorski \& Garber, 2012). The difficulties that participants spoke of in the stories analyzed for this research are similar to those found by other studies looking at the barriers to accessing military mental health services. For example, a barrier identified by military personnel in this study as well as in others, is the concern that disclosing a mental health diagnosis or seeking out mental health services may impact negatively on their career.

This study enhances what is already known about the difficulties to accessing military mental health services by uncovering certain barriers not identified within the existing literature. This includes barriers such as the strict admissions criteria of certain programs which exclude those experiencing more severe symptoms of a mental health diagnosis, gaps in the delivery of service after moving, and drastic circumstances seeming necessary (e.g., suicide attempt) in order to receive services in a timely manner.

Another similarity in the outcomes of this research to those of existing studies is the impact of mental health stigma within the military, specifically as it relates to the difficulties accessing mental health services. The outcomes of this research support that mental health stigma can act as a barrier to seeking mental health services. This is similar to the findings of other studies in which negative stigma has been found to inhibit or deter military personnel from seeking care (Castro et al., 2004; Pietrzak et al., 2009). The outcomes of this study advance knowledge in this area by reinforcing that stigma remains to be an issue experienced and expressed by current and former members of the CAF despite the military's efforts to address and challenge it.

Other studies however, have found that stigma is not reported as a barrier to accessing mental health care (Kim et al., 2011; Sudom, Zamorski \& Garber, 2012) demonstrating that 
findings on the association between stigma and barriers to accessing mental health care are mixed. Reasons for why stigma is not a reported barrier could include that studies did not directly ask about it, power dynamics or fears related to disclosing experiences impeded individuals from speaking about stigma, or that stigma itself acts as a barrier to its exploration.

Other differences also exist when comparing the research outcomes of this study to those of the existing literature. Although themes related to difficulties accessing mental health services are comparable to the findings of other studies, there are differences in the specific barriers identified by military personnel. This study found that common barriers encountered when attempting to access military mental health services included having multiple appointments with different health professionals, needing to provide numerous documents of health and other personal information, requiring numerous referrals, having to meet strict admissions criteria of treatment programs and long wait times. These difficulties represent more structural types of barriers to accessing military mental health services. These types of structural barriers could exist as a result of the increasing demands placed on the military's mental health services due to the large number of CAF personnel who have more recently been exposed to combat, which is linked to receiving a mental health diagnosis (Boulos \& Zamorski, 2013).

Other studies have found however, that attitudinal barriers are more commonly the cause of difficulties accessing military mental health care. These attitudinal barriers include negative attitudes toward mental health treatment, beliefs that services would be ineffective or harmful, desires to self-manage mental health issues, lack of trust in military health, administrative, and social services, and as previously mentioned, concerns about career impact of seeking care and negative stigma (Castro et al., 2004; Fikretoglu et al., 2008; Kim et al., 2011; National Defence and the Canadian Armed Forces, 2013b; Sudom, Zamorski \& Garber, 2012). 
These differences in the barriers to accessing military mental health services are interesting. Those expressed by participants in this study indicate that the issue exists within the actual mental health services being sought - that there are structural barriers to accessing mental health care. The barriers identified by other studies however, seem to suggest that the issue exists within military personnel themselves - that there are attitudinal barriers to accessing mental health care. In a study conducted by the Department of National Defence (2010 as cited in Kim et al., 2011) it was found that structural factors are not prevalent reported barriers in the CAF due to the heavy investments made to its mental health system over the past decade. The outcomes of this study show however, that structural issues still exist and that often it is these more practical difficulties that act as barriers to accessing the CAF's mental health services.

These differences in findings could be the result of methodological differences. Whereas other studies used quantitative methods of data collection such as surveys and questionnaires, this study used a narrative approach in the methods of data collection and analysis. In this approach, greater emphasis is placed on exploring and learning from the stories and experiences of participants which allows for more in-depth and detailed information to be collected (Chase, 2011). This approach is also a way to value the knowledge of participants as they are viewed as experts of their own lives and experiences (Dominelli, 2002). This allows participants to become active contributors to the construction of knowledge about topics of which they have lived experience (Potts \& Brown, 2005).

Further, most of the other studies reviewed were conducted by military researchers. This could potentially impact on participants' responses as they are required to share personal opinions about their employer. As previously mentioned, it is important to consider the power dynamics involved in research that is conducted with military personnel by military researchers. 
In such instances, participants may not be truthful or entirely forthcoming about their opinions or experiences for fear that such information could negatively impact upon their careers. These power dynamics can then affect the findings of these studies. The data used for this research however, came from interviews conducted by civilian reporters. This could have allowed individuals, particularly those still employed by the CAF, to feel more at ease about disclosing information about their experiences. Here again, an AOP perspective allows for an understanding of the impact of power dynamics (Mullaly, 2002) particularly as they relate to conducting research. Research guided by an AOP approach is attuned to the power differences built into the research process and as such, researchers strive to design procedures and methodologies that can make research a more egalitarian endeavour (Strier, 2007). Understanding the influence of power dynamics in research help to inform how a study's design and methods can impact on its outcomes. This understanding was beneficial as it allowed me to design and conduct my study in a way that issues of power were minimized and thereby less likely to affect the research findings - something that has not been accounted for in studies conducted by military researchers.

Taken together, the outcomes of this research can be interpreted in ways that relate to the theoretical framework, methodology and literature that guided this project. Interpretations can also be made about the research process that unfolded while completing this project.

\subsection{The Research Process}

The process of conducting this research project inadvertently became a story of its own. As has been previously mentioned, I began this research with the intention of completing it a certain way. However, the challenges encountered when attempting to access the population and recruit participants required a shift in methods. The challenges encountered during the research process can be interpreted in a number of ways. 
The challenges that arose began during the recruitment stage of this research project. I had a difficult time finding recruitment sources that were willing to support my research by advertising or distributing my recruitment poster. This could be because most research on topics related to military matters is conducted by military researchers from the Department of National Defence. Conducting research on or through government run organizations such as the CAF requires approval from a separate research ethics board. It was for this reason that I sought out a number of non-governmental recruitment sources. Despite this, I still encountered some resistance from these sources. This is perhaps because the individuals and agencies I contacted did not view a study being completed by a graduate student as legitimate research. Other possibilities include that as a civilian, I may have been viewed as an outsider and the insular and protective culture of the CAF may prevent civilians from accessing information on or about military matters (Ben-Ari \& Levy, 2014). Additionally, military organizations and agencies may not feel that civilians have an understanding of military life or circumstances and as such may question their suitability to conduct research concerning military issues.

I also experienced challenges recruiting participants even after having had some success with getting my recruitment poster advertised or distributed. I would interpret that this could be due to the sensitive nature of the topic. For many, sharing personal accounts of their experience with mental health care can be difficult and doing so for the purpose of a research study may not have been desirable.

The stigma surrounding mental health, compounded by the military culture, may have also prevented individuals from coming forward and sharing their stories. As the outcomes of this study suggest, the fear of being stigmatized due to a mental health diagnosis acts as a barrier to seeking and accessing military mental health services (Castro et al., 2004; National Defence 
and the Canadian Armed Forces, 2013b). This fear of being stigmatized may have also impeded individuals from wanting to participate in this study as the risk of being identified as an individual may have been perceived to be too great.

Participating in this research study may have also been viewed as an economic risk, particularly by those currently employed by the CAF. Current CAF members may not feel comfortable speaking out about the experiences they have had with their employer's mental health services, especially if those experiences were negative. Individuals may have been concerned about being identified in a study that would require them to disclose a mental health issue and discuss their experiences with their employer's mental health services. This may have led to concerns about the potential for job loss if identified. Previous studies have found that fears related to negative career repercussions, such as job loss, are a concern for military personnel affected by issues of mental health (Castro et al., 2004; Fikretoglu et al., 2008; National Defence and the Canadian Armed Forces, 2013b).

I interpret that it is for these reasons that challenges accessing the population and recruiting participants for this research project were encountered. Despite these challenges, I was able to modify aspects of the methodology in ways that allowed me to answer the research question guiding this study.

\subsection{Answering the Research Question}

Although challenges were encountered during the research process, they did not inhibit my ability to answer the research question guiding this study. Through collecting media sources where current and former CAF members are interviewed about their experiences with the CAF's mental health services, I was able to analyze and interpret the information they shared in ways that help to answer the research question. Identifying themes that emerged within these 
individuals' stories helped make clear what the experience of receiving mental health services within the CAF is like from their perspective. Completing this process also assisted with exploring whether and how AOP social work can contribute to or enhance the CAF's current mental health services. This is discussed later in the chapter as an implication of this research.

This study sought to explore what the stories of current or former CAF personnel can inform us about the experience receiving mental health services within the CAF. The outcomes of this research detail a number of themes that emerged within participants' stories that provide insight about this experience. Included among these themes are the difficulties experienced when attempting to access the CAF's mental health services, the negative effects of mental health stigma, fears related to disclosing a mental health issue and that changes are needed to the CAF's mental health system.

There were however, gaps in my ability to answer the research question due to certain challenges encountered during the research process and as such it is important to consider the limitations of this study.

\subsection{Limitations}

A first limitation of this study is the use of data that was not collected directly from participants. As previously mentioned, I was unable to conduct in-person interviews due to the difficulties encountered when attempting to access the population and recruit participants and as such, the study relies on secondary data. I was limited to using media sources in which interviews were conducted with current or former CAF members about their experiences with the CAF's mental health services. This secondary data does not provide the same rich and indepth information that may have been uncovered by conducting in-person interviews (Creswell, 2013). 
Another limitation of this research relates to the process of data analysis used. There are few studies using thematic narrative analysis that detail the step-by-step process that was undertaken to complete data analysis (Chase, 2011; Riessman, 2005). As a result, I was required to devise my own process for doing thematic narrative analysis in a way that would best fit my research aims. This is as opposed to relying on a more well-established and documented process. Although this is indeed a limitation, it can also be considered a strength, as using this approach allows for the analysis to fit the research rather than having it be confined to a prescribed method.

There are also criticisms of thematic analysis which must also be acknowledged as a limitation of this study. In thematic analysis, readers must assume that when many narratives are grouped into a similar theme that everyone in the group means the same thing based on what they say (Riessman, 2005). Doing so however, neglects to consider the ambiguities, "deviant," or unspoken responses that do not fit into any particular theme (Riessman, 2005). Attempts were made to minimize this limitation by primarily doing within-case analyses of participants' stories as opposed to grouping multiple narratives together to create across-case themes. However, there is still the possibility that even when doing within-case analyses, ambiguous or deviant responses that do not fit into the themes emerging within a participant's story can be left out.

Another limitation of this study is the lack of diversity in the mental health diagnoses experienced by participants. All of the participants in this study had a diagnosis of PTSD which represents only one of the more prevalent types of mental health issues experienced by military personnel (Boulos \& Zamorski, 2013; Fikretoglu et al., 2007; Sareen et al., 2008). As such, we are unable to learn about the experience of receiving mental health services for those current or 
former CAF members who have diagnoses other than PTSD or whether there are any differences in experience based on type of mental health diagnosis.

This research study is also limited due to its smaller scope and sample size. Only seven participant stories were analyzed and as such the research outcomes only represent the experiences of a small number of current or former CAF members. Further, the findings of this study are limited to what was available in the narrative units analysed. As data came from preexisting interviews, I was unable to probe for more detailed and robust information. Although these limitations are important to consider, various efforts were undertaken to support the authenticity of this research project.

\subsection{Authenticity of the Research}

The authenticity of this research can be demonstrated by the ways in which it meets certain evaluative standards necessary in qualitative research as well as by its methodological rigour. This requires examining the evidence of quality that has emerged following the completion of the study as well as the deliberate efforts that were built into the study's design to improve quality (Padgett, 2008).

There are a number of perspectives on the evaluation criteria of qualitative research (Creswell, 2013). For the purpose of this study, I follow the evaluation criteria identified by Richardson and St. Pierre (2005) who utilize an interpretive standards perspective of conducting qualitative research. I have selected to use this approach because the evaluative criteria are largely concerned with meaning and interpretation which fits well with narrative research (Creswell, 2013). Further, these criteria are consistent with principles of AOP which can be seen through their focus on the social contributions and impact of a piece of research and the need for reflexivity of the researcher (Baines, 2011; Richardson \& St. Pierre, 2005). 
Whether a study substantively contributes to social life is the first criterion necessary for meeting the evaluative standards of qualitative research (Richardson \& St. Pierre, 2005). This study can be seen to meet this criterion as it offers insight on the experience of receiving mental health services within the CAF. By doing so, it contributes to the knowledge surrounding an aspect of social life, specifically the area of military mental health and mental health services.

Another criterion used for the evaluation of qualitative research is whether a study uses creative analytical practices that open up the text and invite interpretive responses (Richardson \& St. Pierre, 2005). This study required the development of a unique process of thematic narrative analysis that was designed specifically to meet the aims of this research. The analytical process that was developed involved a close examination of the narrative texts so that interpretations of themes could be made. In this way, the analytical practices used in this study can be seen to satisfy this criterion of evaluative standards.

How a researcher's subjectivity has been both a producer and a product of the text is another criterion for evaluating qualitative research (Richardson \& St. Pierre, 2005). Within the MRP, I purposefully write about my own subjectivity by providing information about the influence of my personal connection to the research topic. In this way, I demonstrate a level of reflexivity that is necessary for meeting the evaluative standards of qualitative research.

Finally, the impact of a study is another criterion identified as an evaluative standard of qualitative research (Richardson \& St. Pierre, 2005). This criterion considers whether a piece of research has an emotional effect on readers, generates new questions, or moves others to take action (Richardson \& St. Pierre, 2005). Although I cannot speak to whether and how this research is impactful for readers, I can attest that it has impacted upon me as a researcher. Completing this study has influenced me to continue pursuing a career as a military social 
worker. The study has assisted me to better understand the experience of receiving mental health services within the CAF and offered insight on how services can be provided in positive and beneficial ways. Further, this study is also impactful by bringing an AOP lens to an environment that might not otherwise be explored in this way. Although preliminary in its nature, this research has demonstrated that there is value to exploring the relevancy of AOP within a military context and for its potential to contribute to mental health services within the CAF.

The authenticity of this study is also enhanced by the efforts undertaken to incorporate various strategies of rigour directly into the research design. One such strategy is that of interdisciplinary triangulation which refers to using more than one discipline in a single study (Janesick, 2000). The use of an AOP approach as the theoretical framework guiding the study can be seen to parallel this concept of interdisciplinary triangulation. Due to its broad and comprehensive approach, AOP brings in various perspectives from other disciplines so as to avoid disciplinary bias and enhance rigour.

Another strategy for rigour used in this research project is that of peer debriefing and support (Creswell, 2013). Throughout this research project, I relied on the support and guidance of my MRP supervisor and peers within the MSW program. These individuals provided emotional support and understanding, offered ideas and feedback and helped to keep me honest about my research. Utilizing these types of support worked to further enhance the rigour of this study.

Finally, this research project also demonstrates rigour by leaving an audit trail documenting each step taken during the stages of data collection and analysis (Creswell, 2013). The methods and process of my data collection and analysis are thoroughly detailed in this MRP so as to be open and honest with readers about the exact steps that were taken. Further, readers 
can view the interview transcripts of participants by looking up the newspaper articles and news series from which they were drawn. These media sources are clearly identified in the methodology chapter of this MRP.

Considering the ways in which this study meets the evaluative standards of qualitative research and detailing how strategies of rigour were incorporated into the research design and process, assists in demonstrating its authenticity.

\subsection{Implications}

This study has several implications relevant to social work practice. The outcomes of this research provide insight into what the experience of receiving mental health services within the CAF is like for current and former military members. The primary benefit of these outcomes are for social workers interested in working or currently practicing with military populations, particularly in the area of mental health. These social workers are able to learn, from service users, what the experience receiving mental health services is like. Knowing about the more positive experiences of receiving mental health services can inform practitioners about what is being done well while understanding what contributes to negative experiences can assist them with finding ways to improve how services are delivered. Overall, this research offers both military and civilian social workers working with military personnel affected by issues of mental health new insights that can assist them with their practice.

Another aim of this research was to explore whether and how AOP social work can contribute to or enhance the CAF's current mental health services. As such, another implication of this study is that it offers a preliminary exploration of how social workers can incorporate certain methods and strategies of AOP into their work in ways that could benefit the CAF's mental health services. 
The outcomes of this study suggest that one way of incorporating AOP social work into the CAF's mental health services is through advocacy. Participants spoke about the importance of having someone to advocate for them in order to receive the type of mental health services they needed. This is a role that military and civilian social workers can undertake as part of their practice either individually or collectively. Advocacy could involve engaging in efforts on behalf of individual service users to ensure that they receive needed services or could take the form of more large scale advocacy efforts such as organizational or policy change.

The outcomes of this study also suggest that another way in which AOP social work could contribute to the CAF's mental health services is by furthering efforts aimed at challenging mental health stigma. Although the CAF has put in place various efforts aimed at reducing stigma, AOP social workers can offer additional perspectives and strategies. AOP social workers are well positioned to facilitate efforts aimed at challenging mental health stigma as a result of their extensive education and training in forms of social oppression. Efforts could include promoting education, encouraging the use of respectful language and discourse, identifying and challenging sanism, and deconstructing the medical model, among others.

This study also has methodological implications for future research. As the story of completing this research process shows, civilian researchers can encounter challenges when attempting to conduct research related to military issues. This study helps to inform future researchers about these challenges by detailing the difficulties experienced when attempting to access a military population and recruit participants. This can assist future researchers interested in conducting research on topics related to military matters by informing them about how to approach or design their studies. This could involve choosing a methodology or method of data collection that does not require interviews, in consideration of the challenges I noted. 
It is recommended that future research continue to explore the ways in which AOP social work can contribute to the CAF's mental health services. Research that involves hearing from military and civilian social workers who work with military populations to learn about if and how they incorporate methods and strategies of AOP into their practice could offer additional insight. It is also recommended that future research explore ways of addressing some of the barriers to accessing the CAF's mental health services that were identified by participants in this study. This could assist with improving the delivery of military mental health services. Also recommended is further independent research where the voices of current and former CAF personnel are heard. Research regarding the challenges of civilian researchers accessing military populations would also be recommended as this was an issue encountered during the process of completing this study.

This chapter presented a discussion of my interpretations of the research outcomes and process of this study. Outcomes were interpreted specifically as they relate to the theoretical framework, methodology and literature guiding the research. The limitations and authenticity of this study were also discussed. Finally, the implications of this research for social work practice and recommendations for future research were also presented. 


\section{CONCLUSION}

Much can be learned about the CAF's mental health services by exploring the experiences of those who have received them. The narratives of current and former CAF personnel offer rich and detailed information that previous studies have failed to access. My intention with this study was to centre the stories of these individuals to examine and interpret how they can inform us about the experience of receiving mental health services within the CAF. As these narratives reveal, various themes emerge within each individual participant's story that offer insight about their experience.

Although themes differed within each story, certain similarities in themes included the experience of structural difficulties when attempting to access the CAF's mental health services, the negative effects of mental health stigma, fears related to disclosing issues of mental health and the need for changes to the CAF's mental health system. The process of completing this research also inadvertently became a story of its own due to the challenges encountered when attempting to access the population and recruit participants for this study.

These narratives are also useful in guiding a preliminary discussion exploring the relevance of AOP social work for the CAF's mental health services. Themes within participants' stories help to inform ways in which this practice approach can contribute to how these services are currently delivered. Narratives reveal that contributions can include engaging in efforts aimed at advocacy and forwarding efforts to challenge negative mental health stigma.

While these narratives provide insight into the experience of receiving the CAF's mental health services and the relevancy of AOP social work in this practice context, there is still a substantial amount of information pertaining to these areas that has yet to be uncovered. As such, I encourage future research to continue exploring these topic areas. Future research is also needed to explore how civilian researchers can best access potential participants for studies 
related to military issues. In doing so, we share the ultimate aim of ensuring that our current and former Canadian service men and women receive the best mental health care available. 


\section{APPENDIX A}

\section{RYERSON}

UNIVERSITY

\section{SCHOOL OF SOCIAL WORK \\ FACULTY OF COMMUNITY SERVICES}

Accredited by the Canadian Association for Social Work Education

\section{Seeking Participants for a Study on Experiences with the Canadian Armed Forces' Mental Health Services}

I am looking for volunteers to take part in a study about the experience of
receiving mental health services within the Canadian Armed Forces.

I am a graduate student in social work, and this study forms part of my graduate work.

You would be asked to participate in an interview where you will be asked questions about your experience with receiving mental health services within the Canadian Armed Forces.

Your participation would involve one interview session by phone or in person, which will be about 1 hour long.

For more information about this study, or to volunteer for this study, please contact:

Erin O'Rourke

School of Social Work

Email: erin.orourke@ryerson.ca

This study has been reviewed by, and received ethics clearance by the Ryerson Research Ethics Board.

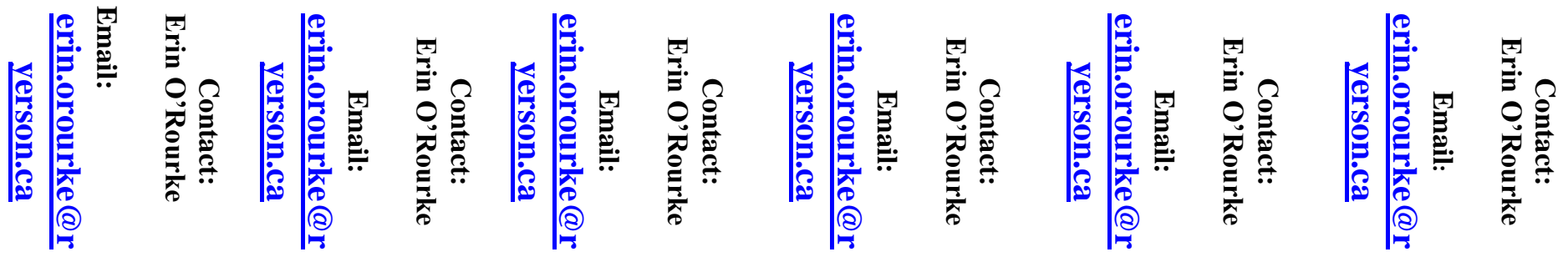




\begin{abstract}
APPENDIX B
The following document is the interview guide that would have been used for the originally intended method of data collection.

\section{Exploring the Experience of Receiving Canadian Armed Forces' Mental Health Services}

*Please Note: Interviews may also include the use of probing questions (i.e. Can you tell me more about this? Can you help me to understand this better?), depending on the direction of the interview.
\end{abstract}

Preamble: Thank you for agreeing to be part of this research process. Before we start, I would like you to know that this interview will take approximately one hour. I also want to assure you that everything you say here is confidential, unless you tell me you plan to harm yourself or someone else. Otherwise, only I will have access to the information you provide, with the exception of my research supervisor. All identifying information will be removed from your transcript and a pseudonym will be used if you are quoted. Before we begin, I would like to ask your permission to record the interview. At any point during the interview, you may ask to stop the recording or take a break. You can also terminate the interview at any point if you feel any discomfort or you decide to change your mind about being part of this research study. Do you have any questions before we begin?

1) Can you tell me a bit about your involvement with the CF?
a) When did you join?
b) What type of work did/do you do?

2) Can you tell me about when you first started experiencing any concerns about your mental health?

a) What did you do when you first became concerned (i.e. talk to family or friends, commanding officers, look into services/supports?)

3) Can you share with me what your experience was like receiving mental health services from the CF?

a) How long after you became concerned about your mental health did you first receive service?

b) What, if anything, was positive about the experience? What have/did you find helpful?

c) What, if anything, was negative about the experience? What have/did you find unhelpful? 
4) If you could choose between receiving mental health services from the CF or from a civilian agency, which would you prefer? Why?

Part of what I am trying to understand with my research is whether or not a particular approach to social work practice might be helpful. I am going to explain that approach briefly here before I ask you any more questions.

Anti-oppression is a type of social work practice that focuses on areas that include power, identity and language. It also looks at how types of oppression (e.g., racism, sexism) create and affect the social problems people experience in their lives. These next few questions will touch on some of these areas as they relate to your experiences receiving mental health services within the CF.

5) In what ways did/does the hierarchical power structure of the military affect your experience receiving mental health services?

6) In what ways did/do aspects of your social identity such as your gender, ethnicity, and/or disability status affect your experience receiving mental health services?

7) In what ways did/does the language and/or discourse used within the CF's mental health services affect your experience receiving them? (i.e. being labelled with a "diagnosis")

8) In what ways did/do larger forces such as the stigma surrounding issues of mental health, affect your experience receiving mental health services?

9) If you were to access mental health services with the CF again, how would you like to see those services delivered?

10) That's the end of my questions. Is there anything else you want to share with me?

11) Do you have any questions? 


\section{APPENDIX C}

This document is an example of how I constructed my transcripts for data analysis.

Media Source: The Chronicle Herald

Title: Veteran urges upgrade of mental-health services available to Canadian Forces personnel

Date: January 25, 2014

Author: Michael Lightstone

\begin{tabular}{|c|c|c|}
\hline $\begin{array}{c}\text { Participant Name } \\
\text { Tim Boyce }\end{array}$ & Transcript & Memos \\
\hline (Tim) & $\begin{array}{l}\text { The Montreal native lives alone at } 12 \text { Wing } \\
\text { Shearwater. He said he served with the Armed } \\
\text { Forces in Syria (2005), Kosovo (2000), } \\
\text { Bosnia (1998) and Croatia (1993-94). }\end{array}$ & $\begin{array}{l}\text { Text from the article that makes } \\
\text { up the participant's narrative is } \\
\text { placed in the "transcript" column. } \\
\text { This includes text related to the } \\
\text { participant's military } \\
\text { involvement, when they were first } \\
\text { diagnosed or began experiencing } \\
\text { symptoms of a mental health } \\
\text { issue, how the mental health issue } \\
\text { has impacted on their life and } \\
\text { their experiences with the CAF's } \\
\text { mental health services. }\end{array}$ \\
\hline (Tim)/Tim & $\begin{array}{l}\text { Though he acknowledged his case is complex, } \\
\text { and he hasn't "been the perfect soldier" - } \\
\text { Boyce in } 2011 \text { was charged with being absent } \\
\text { without leave and received a caution from a } \\
\text { military court - he said he's proud of his } \\
\text { accomplishments, which include seeing his } \\
\text { infantry trainees move on to use crucial skills } \\
\text { they've learned. }\end{array}$ & \\
\hline (Tim) & $\begin{array}{l}\text { Tim is due for a medical release from the } \\
\text { military at the end of March. }\end{array}$ & \\
\hline (Tim) & $\begin{array}{l}\text { While in the Canadian Forces in 2006, he was } \\
\text { diagnosed with several emotional problems } \\
\text { including post-traumatic stress disorder. }\end{array}$ & \\
\hline (Tim) & $\begin{array}{l}\text { Tim said his war-zone experiences led to } \\
\text { post-traumatic stress, and his quality of life in } \\
\text { recent years has been dismal }\end{array}$ & \\
\hline (Tim) & $\begin{array}{l}\text { He said he's attempted suicide more than } \\
\text { once, can't tolerate confined spaces such as } \\
\text { passenger train cars and planes, and does his } \\
\text { grocery shopping at } 3 \text { a.m. to avoid crowds. } \\
\text { He said four military comrades who he's } \\
\text { known personally have committed suicide. }\end{array}$ & \\
\hline
\end{tabular}




\begin{tabular}{|c|c|c|}
\hline (Tim) & $\begin{array}{l}\text { His mental state is such that he lives in a } \\
\text { home with blacked-out windows. He said he } \\
\text { has no friends - only acquaintances - and is } \\
\text { incapable of maintaining close relationships } \\
\text { with family members. }\end{array}$ & \\
\hline (Tim) & $\begin{array}{l}\text { Tim said he can't sleep and doesn't trust } \\
\text { anyone. }\end{array}$ & \\
\hline (Tim) & $\begin{array}{l}\text { His marriage has dissolved; his wife and } \\
\text { seven-year-old daughter live outside the } \\
\text { Halifax region. }\end{array}$ & \\
\hline Tim & $\begin{array}{l}\text { "I have a daughter I seldom see because I } \\
\text { can't handle it," he wrote in a journal, a copy } \\
\text { of which he recently provided to this } \\
\text { newspaper. }\end{array}$ & \\
\hline Tim & $\begin{array}{l}\text { "I love her deeply and talk to her daily, but } \\
\text { conversations with seven-year-olds don't last } \\
\text { too long. I'll eventually have to explain to her } \\
\text { when she's older why Daddy wasn't there } \\
\text { while she (was) growing up." }\end{array}$ & \\
\hline (Tim) & $\begin{array}{l}\text { Another issue has been addictions. Boyce said } \\
\text { he's lost a considerable amount of money at } \\
\text { the casino in Halifax and volunteered to have } \\
\text { officials there bar him from the premises. }\end{array}$ & \\
\hline (Tim) & $\begin{array}{l}\text { Asked what memories trigger his PTSD, Tim } \\
\text { said he can't be around children who are } \\
\text { crying because of horrific incidents he said } \\
\text { happened when he was serving overseas. }\end{array}$ & \\
\hline (Tim) & $\begin{array}{l}\text { He said two episodes in Croatia still deeply } \\
\text { affect him. }\end{array}$ & \\
\hline Tim & $\begin{array}{l}\text { "We had binoculars and I was watching this } \\
\text { field where kids were playing, and a shell } \\
\text { landed in it, and it just got them," Tim said. }\end{array}$ & \\
\hline Tim & $\begin{array}{l}\text { "It killed those kids. All of a sudden, I see the } \\
\text { parents running out and picking up these dead } \\
\text { bodies and it just got to me." }\end{array}$ & \\
\hline (Tim) & $\begin{array}{l}\text { Another incident involved a friendly, six- } \\
\text { year-old boy Boyce said used to come by his } \\
\text { army camp and "knew the rotation" of } \\
\text { soldiers on guard duty. }\end{array}$ & \\
\hline Tim & $\begin{array}{l}\text { "This kid - he walked into a minefield," he } \\
\text { said. "I saw them drag him out of there." }\end{array}$ & \\
\hline Tim/(Tim) & $\begin{array}{l}\text { "I have good days and bad," Boyce told The } \\
\text { Chronicle Herald, adding, people reading this } \\
\text { story may think he's "whining" about his } \\
\text { misfortune. }\end{array}$ & \\
\hline
\end{tabular}




\begin{tabular}{|l|l|l|}
\hline (Tim) & $\begin{array}{l}\text { Boyce, a 46-year-old army sergeant and } \\
\text { former infantry instructor, said Saturday his } \\
\text { journey through the military's mental-health } \\
\text { system has been extremely challenging at } \\
\text { best, exacerbating at worst. }\end{array}$ & $\begin{array}{l}\text { Highlighted areas are parts of the } \\
\text { narrative where themes related to } \\
\text { the research question emerge. } \\
\text { Difficult journey through military } \\
\text { mental health services }\end{array}$ \\
\hline Tim/(Tim) & $\begin{array}{l}\text { Boyce said he has consulted dozens of } \\
\text { medical professionals in the Forces and in the } \\
\text { civilian mental-health system. Some were } \\
\text { very caring, but many others, he said, "didn't } \\
\text { do their jobs" and he fell through the cracks. }\end{array}$ & $\begin{array}{l}\text { Numerous consultations with } \\
\text { service providers } \\
\text { Falling through the cracks }\end{array}$ \\
\hline Tim & $\begin{array}{l}\text { "No, it's not all bad," he said in an interview. } \\
\text { "But the bad situations (in the mental-health } \\
\text { system) outweigh the good ones." }\end{array}$ & $\begin{array}{l}\text { "the bad situations outweigh the } \\
\text { good" }\end{array}$ \\
\hline (Tim) & $\begin{array}{l}\text { Boyce said he's speaking out because, in his } \\
\text { view, the system needs to be reformed to } \\
\text { assist current Armed Forces personnel and } \\
\text { recruits starting their careers, should they } \\
\text { need mental-health help. }\end{array}$ & $\begin{array}{l}\text { Changes to military mental health } \\
\text { system are necessary }\end{array}$ \\
\hline Tim & $\begin{array}{l}\text { "It's too late for me," he said in his typed, } \\
\text { eight-page journal. "But maybe, just maybe, } \\
\text { someone can learn from this and try to fix } \\
\text { things so others don't ever have to go through } \\
\text { this." }\end{array}$ & $\begin{array}{l}\text { Changes to military mental health } \\
\text { system are necessary }\end{array}$ \\
\hline
\end{tabular}




\section{REFERENCES}

Baines, D. (2007). Anti-oppressive social work practice: Fighting for space, fighting for change. In D. Baines (Ed.), Doing anti-oppressive practice: Building transformative politicized social work (pp. 1-30). Halifax: Fernwood Publishing.

Baines, D. (2011). An overview of anti-oppressive practice: Roots, theory, tensions. In D. Baines (Ed.), Doing anti-oppressive practice: Social justice social work (2nd ed.) (pp. 1-24). Halifax: Fernwood Publishing.

Ben-Ari, E., \& Levy, Y. (2014). Getting access to the field: Insider/outsider perspectives. In J. Soeters, P. Shields, \& S. Rietjens (Eds.), Routledge handbook of research methods in military studies (pp. 9-18). New York: Routledge

Bold, C. (2012). Using narrative in research. Thousand Oaks, CA: Sage Publications Ltd.

Boulos, D., \& Zamorski, M. (2013). Deployment-related mental disorders among Canadian Forces personnel deployed in support of the mission in Afghanistan, 2001-2008. Canadian Medical Association Journal, 185 (11), 545-552.

Castro, C., Cotting, D., Hoge, C., Koffman, R., McGurk, D., \& Messer, S. (2004). Combat duty in Iraq and Afghanistan, mental health problems, and barriers to care. The New England Journal of Medicine, 351(1), 13-22.

Chase, S. (2003). Learning to listen: Narrative principles in a qualitative research methods course. In R. Josselson, A. Lieblich \& D. McAdams (Eds.), Up close and personal: The teaching and learning of narrative research (pp. 79-99). Washington, DC: American Psychological Association. 
Chase, S. (2011). Narrative inquiry: Multiple lenses, approaches, voices. In N.K. Denzin \& Y. S. Lincoln (Eds.), The SAGE handbook of qualitative research (4th ed., pp. 651-679). Thousand Oaks, CA: Sage Publications, Inc.

Clandinin, D. J., \& Connelly, F. M. (2000). Narrative inquiry: Experience and story in qualitative research. San Francisco, CA: Jossey-Bass Publishers.

Creswell, J. W. (2013). Qualitative inquiry and research design: Choosing among five approaches (3rd ed.). Thousand Oaks, CA: Sage Publications, Inc.

Drapalski, A., Milford, J., Goldberg, R., Brown, C., \& Dixon, L. (2008). Perceived barriers to medical care and mental health care among veterans with serious mental illness. Psychiatric Services, 59(8), 921-924.

Dominelli, L. (2002). Anti-oppressive social work theory and practice. New York, NY: Palgrave Macmillan.

Elbogen, E., Wagner, R., Johnson, S., Kinneer, P., Kang, H., Vasterling, J., Beckham, J. (2013). Are Iraq and Afghanistan veterans using mental health services? New data from a national-random sample survey. Psychiatric Services, 64(2), 134-141.

Elliott, L. (2010, May 25). Soldiers with severe PTSD have trouble finding help. Canadian Broadcasting Company. Retrieved from http://www.cbc.ca

Fear, N., Jones, M. Murphy, D., Hull, L., Iverson, A., Coker, B.,.\& Wessely, S. (2010). What are the consequences of deployment to Iraq and Afghanistan on the mental health of the UK Armed Forces? A cohort study. The Lancet, 375(9728), 1783-1797. 
Fikretoglu, D., Brunet, A., Guay, S., \& Pedlar, D. (2007). Mental health treatment seeking by military members with posttraumatic stress disorder: Findings on rates, characteristics, and predictors from a nationally representative Canadian military sample. Canadian Journal of Psychiatry, 52(2), 103-110.

Fikretoglu, D., Brunet, A., Guay, S., \& Pedlar, D. (2008). Twelve month use of mental health services in a nationally representative, active military sample. Medical Care, 48(2), 217223.

Fikretoglu, D., Liu A., Pedlar D., \& Brunet A. (2010). Patterns and predictors of treatment delay for mental disorders in a nationally representative, active Canadian military sample. Medical Care, 48(1), 10-17.

Fraser, H. (2004). Doing narrative research: Analysing personal stories line by line. Qualitative Social Research, 3(2), 179-201.

Hoge, C., Auchterlonie, J., \& Milliken, C. (2006). Mental health problems, use of mental health services, and attrition from military service after returning from deployment to Iraq or Afghanistan. Journal of the American Medical Association, 295, 1023-1032.

Healy, K. (2005). Social work theories in context: Creating frameworks for practice. New York, NY: Palgrave Macmillan.

Janesick, V. J. (2000). The choreography of qualitative research designs: Minuets, improvisations and crystallization. In N. K. Denzin \& Y. S. Lincoln (Eds.), Handbook of qualitative research (pp. 379-400). Thousand Oaks, CA: Sage Publications, Inc.

Johnstone, B. (2008). Discourse analysis and narrative. In D. Schiffrin, D. Tannen \& H. Hamilton (Eds.), The handbook of discourse analysis (pp. 635-650). Oxford, UK: Blackwell Publishers Ltd. 
Kim, P., Britt, T., Klocko, R., Riviere, L., \& Adler, A. (2011). Stigma, negative attitudes about treatment, and utilization of mental health care among soldiers. Military Psychology, 23, 65-81.

Larson, G. (2008). Anti-oppressive practice in mental health. Journal of Progressive Human Services, 19(1), 39-54.

Liamputtong, P. (2007). Researching the vulnerable. Thousand Oaks, CA: Sage Publications Inc.

Lightstone, M. (2014, January 25). Veteran urges upgrade of mental-health services available to Canadian Forces personnel. The Chronicle Herald. Retrieved from http://thechronicleherald.ca/metro/1182253-veteran-urges-upgrade-of-mental-healthservices-available-to-canadian-forces-personnel

Loney, H. (2014, April 15). Invisible Wounds. Global News. Retrieved from http:/globalnews.ca/invisible-wounds/1257394/invisible-wounds/

Neuman, L. \& Robson, K. (2009). Basics of social research: Qualitative and quantitative approaches (Canadian ed.).Toronto: Pearson Allyn \& Bacon.

Milliken, C., Auchterlonie, J., \&Hoge, C. (2007).Longitudinal assessment of mental health problems among active and reserve component soldiers returning from the Iraq war. Journal of the American Medical Association, 298, 2141-2148.

Mullaly, B. (2002). Challenging oppression: A critical social work approach. Toronto: Oxford University Press.

National Defence and the Canadian Armed Forces (2013a). Statement by General Lawson on mental health in the Canadian Armed Forces [Video file].Retrieved from http://www.forces.gc.ca/en/video.page?doc=statement-by-general-lawson-on-mentalhealth-in-the-canadian-armed-forces/hosl5n9p 
National Defence and the Canadian Armed Forces (2013b). Surgeon General's Mental Health Strategy. Retrieved from http://www.forces.gc.ca/assets/FORCES_Internet/docs/en/about-reports-pubshealth/surg-gen-mental-health-strategy.pdf

Padgett, D. (2008). Qualitative methods in social work research (2nd ed.). Thousand Oaks, CA: Sage Publications, Inc.

Pellicer, L. (2013, December 5). Canadian soldiers fight mental-health stigma. Canadian Broadcasting Corporation. Retrieved from http://www.cbc.ca/news/canada/montreal/canadian-soldiers-fight-mental-health-stigma1.2452120

Pietrzak, R. H., Johnson, D. C., Goldstein, M. B., Malley, J. C., \& Southwick, S. M. (2009). Perceived stigma and barriers to mental health care utilization among OEF-OIF veterans. Psychiatric Services, 60(8), 1118-1121.

Poole, J., Jivraj, T., Arslanian, A., Bellows, K., Chiasson, S. Hakimy, H., \&.Reid, J. (2012). Sanism, 'mental health', and social work/education: A review and call to action. Intersectionalities, 1, 20-36.

Potts, K. \& Brown, S. (2005). Becoming an anti-oppressive researcher. In L. Brown \& S. Strega (Eds.), Research as resistance: critical, indigenous and anti-oppressive approaches (pp. 255-287). Toronto: Canadian Scholars Press.

Razack, N., \& Jeffrey, D. (2002).Critical race discourse and tenets for social work. Canadian Social Work Review, 19(2), 257-271. 
Richardson, L., \& St. Pierre, E. A. (2005). Writing: A method of inquiry. In N. K. Denzin \& Y. S. Lincoln (Eds.), The Sage handbook of qualitative research (3rd ed.)(pp. 959-978). Thousand Oaks, CA: Sage Publications Inc.

Riessman, C. (2005). Narrative analysis. In N. Kelly, C. Horrocks, K. Milnes, B. Roberts \& D. Robinson (Eds.), Narrative, memory and everyday life (pp. 1-7). University of Huddersfield.

Riessman, C. (2007). Narrative methods for the human sciences. Thousand Oaks, CA: Sage Publications Inc.

Riessman, C. \& Quinney, L. (2005). Narrative in social work: A critical review. Qualitative Social Work, 4(4), 391-412.

Sakamoto, I. \& Pitner, R. (2005). Use of critical consciousness in anti-oppressive social work practice: Disentangling power dynamics at personal and structural levels. British Journal of Social Work, 35(4), 420-437.

Sareen, J., Belik, S., Afifi, T., Asmundson, G., Cox, B., \& Stein, M. (2008). Canadian military personnel's population attributable fractions of mental disorders and mental health service use associated with combat and peacekeeping operations. American Journal of Public Health, 98(12), 2191-2198.

Sareen, J., Cox, B., Afifi, T., Stein, M., Belik, S., Meadows, G., \& Asmundson, G. (2007). Combat and peacekeeping operations in relation to prevalence of mental disorders and perceived need for mental health care. American Medical Association, 64(7), 843-852. 
Seal, K., Metzler, T., Gima, K., Bertenthal, B., Maguen, S., \& Marmar, C. (2009). Trends and risk factors for mental health diagnoses among Iraq and Afghanistan veterans using Department of Veterans Affairs health care, 2002-2008. American Journal of Public Health, 99(9), 1651-1658.

Smith, K. (2011). Occupied spaces: Unmapping standardized assessments in health and social service organizations. In D. Baines (Ed.), Doing anti-oppressive practice: Social justice social work (2nd ed.) (pp. 197-208). Halifax: Fernwood Publishing.

Stecker, T., Fortney, J., \& Sherbourne, C. (2011). An intervention to increase mental health treatment engagement among OIF veterans: A pilot trial. Military Medicine, 176(6), 613619.

Strier, R. (2007). Anti-oppressive research in social work: A preliminary definition. British Journal of Social Work, 37, 857-871.

Sudom, K., Zamorski, M., \& Garber, B. (2012). Stigma and barriers to mental health care in deployed Canadian Forces personnel. Military Psychology, 24, 414-431.

Williams, C. (1999). Connecting anti-racist and anti-oppressive theory and practice: Retrenchment or reappraisal? British Journal of Social Work, 29(2), 211-230. 